\title{
Dry versus wet marine particle optical properties: RH dependence of depolarization ratio, backscatter, and extinction from multiwavelength lidar measurements during SALTRACE
}

\author{
Moritz Haarig $^{1}$, Albert Ansmann ${ }^{1}$, Josef Gasteiger ${ }^{2}$, Konrad Kandler ${ }^{3}$, Dietrich Althausen ${ }^{1}$, Holger Baars ${ }^{1}$, \\ Martin Radenz ${ }^{1}$, and David A. Farrell ${ }^{4}$ \\ ${ }^{1}$ Leibniz Institute for Tropospheric Research (TROPOS), Leipzig, Germany \\ ${ }^{2}$ Faculty of Physics, University of Vienna, Vienna, Austria \\ ${ }^{3}$ Technische Universität Darmstadt, Darmstadt, Germany \\ ${ }^{4}$ Caribbean Institute for Meteorology and Hydrology, Bridgetown, Barbados
}

Correspondence to: Moritz Haarig (haarig@tropos.de)

Received: 12 June 2017 - Discussion started: 19 June 2017

Revised: 23 September 2017 - Accepted: 7 October 2017 - Published: 30 November 2017

\begin{abstract}
Triple-wavelength lidar observations of the depolarization ratio and the backscatter coefficient of marine aerosol as a function of relative humidity ( $\mathrm{RH})$ are presented with a 5 min time resolution. The measurements were performed at Barbados $\left(13^{\circ} \mathrm{N}, 59^{\circ} \mathrm{W}\right)$ during the Saharan Aerosol Long-range Transport and Aerosol-Cloud interaction Experiment (SALTRACE) winter campaign in February 2014. The phase transition from spherical sea salt particles to cubic-like sea salt crystals was observed with a polarization lidar. The radiosonde and water-vapor Raman lidar observations show a drop in RH below $50 \%$ in the marine aerosol layer simultaneously with a strong increase in particle linear depolarization ratio, which reaches values up to $0.12 \pm 0.08$ (at $355 \mathrm{~nm}$ ), $0.15 \pm 0.03$ (at $532 \mathrm{~nm}$ ), and $0.10 \pm 0.01$ (at $1064 \mathrm{~nm}$ ). The lidar ratio (extinction-to-backscatter ratio) increased from 19 and $23 \mathrm{sr}$ for spherical sea salt particles to 27 and $25 \mathrm{sr}$ (at 355 and $532 \mathrm{~nm}$, respectively) for cubic-like particle ensembles. Furthermore the scattering enhancement due to hygroscopic growth of the marine aerosol particles under atmospheric conditions was measured. Extinction enhancement factors from 40 to $80 \% \mathrm{RH}$ of $1.94 \pm 0.94$ at $355 \mathrm{~nm}, 3.70 \pm 1.14$ at $532 \mathrm{~nm}$, and $5.37 \pm 1.66$ at $1064 \mathrm{~nm}$ were found. The enhanced depolarization ratios and lidar ratios were compared to modeling studies of cubic sea salt particles.
\end{abstract}

\section{Introduction}

Since more than $70 \%$ of the Earth is covered with water, the optical properties of marine particles must be carefully considered in radiative transfer schemes in global atmospheric models. This includes marine conditions with relative humidity $(\mathrm{RH})<50 \%$, so marine particles get increasingly dry and change their shape and thus their optical properties, as we will demonstrate in this paper. The shape of sea salt particles strongly depends on $\mathrm{RH}$. At typical values of $\mathrm{RH}>80 \%$ in the marine boundary layer (MBL), sea salt particles are liquid solution drops and thus spherical in shape. When $\mathrm{RH}$ decreases below $45 \%$, they crystallize and become mostly cubic-like in shape (Wise et al., 2007), but they will not become absolutely dry. The change in shape leads to different optical properties, especially to changes in the linear depolarization ratio. Spheres have a linear depolarization ratio of ideally zero, while nonspherical particles exhibit higher values (e.g., Murayama et al., 1999; Sakai et al., 2010; Gasteiger et al., 2011; David et al., 2013; Kemppinen et al., 2015a, b). The different optical properties of dry and humid sea salt have to be considered in various applications.

Satellite passive remote sensing as well as ground-based passive remote sensing (AERONET; e.g., Smirnov et al., 2002; Sayer et al., 2012, for marine environments) may sometimes be significantly affected by dry marine particles in marine environments (coastal regions during sea breeze effects). Cubic-like particles have a different scattering phase 
function than spherical particles. Analogous to the mixture of Saharan dust (assumed to be spheroidal in shape) and spherical anthropogenic particles, in the case of marine particles one would need an analysis scheme which considers cubic particles (and related scattering phase function) besides the spherical ones. The same should be considered in lidar inversion methods (e.g., Veselovskii et al., 2010; Müller et al., 2013), when inverting microphysical properties over the oceans and coastal areas. Nonspherical particles can have a sensitive impact on the retrieval products, and thus particle shape has to be carefully considered (Adachi and Buseck, 2015).

Aerosol classification from active remote sensing (Burton et al., 2012; Groß et al., 2013) based on the depolarization ratio will be misleading if dried marine aerosol with a high depolarization ratio is present. The polarization lidar observations used to separate dust from non-dust (e.g., Sugimoto and Lee, 2006; Tesche et al., 2009; Mamouri and Ansmann, $2014,2017)$ rely on the assumption that non-dust aerosol always produces depolarization ratios around 0.05 or less and significant depolarization is only caused by dry irregularly shaped dust particles. The cubic-like sea salt particles will consequently be misinterpreted as dust, leading to an overestimation of the dust concentration. Active remote sensing from satellites (CALIOP and EarthCARE) use the polarization technique to separate aerosol types. Derived optical properties like the extinction coefficient depend on the detection of the correct aerosol type to choose the appropriate lidar ratio (Omar et al., 2009). Dry sea salt particles may not be detected as sea salt but rather misinterpreted as a different aerosol type with a higher lidar ratio, which leads to an overestimation of the extinction coefficient.

The study aims to show the change of the optical properties with RH, i.e., how spherical and cubic-like sea salt particles influence backscatter, extinction, and light depolarization. The change in shape characteristics of marine aerosol can be easily observed with polarization lidar (Murayama et al., 1999; Sakai et al., 2000; Sugimoto et al., 2000). When equipped with water vapor and nitrogen Raman channels the lidar delivers profiles of specific humidity. Combined with regularly available temperature profiles from radiosondes or models, our Raman lidar observations provide RH together with the depolarization ratio and can thus carefully measure changing particle shape effects with $\mathrm{RH}$, as a function of height. The potential of using Raman lidar to study the hygroscopic growth of aerosol particles was demonstrated by Veselovskii et al. (2009) for summer haze on the east coast of the United States. Granados-Muñoz et al. (2015) observed the decrease of depolarization ratio of marine aerosol mixtures with increasing RH over southern Spain.

Sea salt crystallization and deliquescence was observed with a triple-wavelength polarization lidar (Haarig et al., 2017) in the marine aerosol layer (MAL) over the remote tropical Atlantic in the absence of any disturbing anthropogenic impact and lofted Saharan dust layer. In this way, li- dar can provide valuable information on the state of the MAL from the point of view of optical properties. The results are presented and discussed in Sect. 4.1.

By performing triple-wavelength polarization lidar observations, we provide combined information on the shape and size characteristics of marine aerosol ensembles for the modeling community dealing with the optical properties of irregularly shaped mineral dust and sea salt particles (Gasteiger et al., 2011; David et al., 2013; Kemppinen et al., 2015a). Besides the depolarization ratio of the particles, we also deliver extinction-to-backscatter ratios (lidar ratios), which are also sensitive to changing particle properties. The results are presented in Sect. 4.2.

$\mathrm{RH}$ ranged from 40 to more than $80 \%$ in the MAL. Scattering enhancement factors with $\mathrm{RH}$ are measured under these atmospheric conditions. The enhanced backscatter coefficient depicts the hygroscopic growth of the particles in terms of changing optical properties. For pure marine aerosol, the hygroscopic growth factors and thus the backscatter and extinction enhancement are larger compared to cases with mixtures of marine and continental particles (Zieger et al., 2013). This will be presented in Sect. 4.3.

At the beginning (in Sect. 2), we will give an introduction to sea salt aerosol under dry and humid conditions and show examples of sea salt particles collected above Barbados. The lidar measurements in the framework of the Saharan Aerosol Long-range Transport and Aerosol-Cloud interaction Experiment (SALTRACE; Weinzierl et al., 2017) will be described briefly in Sect. 3. Then we will present our observations with a special focus on the phase transition from spherical solution droplets to crystalline sea salt particles and the scattering enhancement factor (Sect. 4). In the discussion (Sect. 5), we compare our results to model calculations.

\section{Sea salt under dry and humid conditions}

The oceans are the source of marine aerosol, which consists mainly of sea salt and organic compounds from the sea surface (Gantt and Meskhidze, 2013). Marine aerosol from sea spray acts as cloud condensation nuclei and ice nucleating particles over the ocean where other types of particles are rare (DeMott et al., 2016; Kristensen et al., 2016). Marine aerosols are found in a wide size range from nanometer $\left(10^{-9} \mathrm{~m}\right)$ up to several micrometer $\left(10^{-5} \mathrm{~m}\right.$; Bates et al., 1998; Dadashazar et al., 2017). The Aitken mode (diameter $<70-80 \mathrm{~nm}$ ) is dominated by organic material emitted from the ocean. New particle formation dominates the accumulation mode $(80-300 \mathrm{~nm})$ and the larger particles are mostly sea salt (e.g., Wex et al., 2016). The sea salt particles may contain some organics on its surface (Middlebrook et al., 1998; Facchini et al., 2008; Laskin et al., 2012; Tervahattu et al., 2002). Size-resolved studies of marine aerosol (up to $2.5 \mu \mathrm{m}$ ) have been performed on Barbados by Wex et al. (2016). They found that the sea spray mode (>300 nm) 

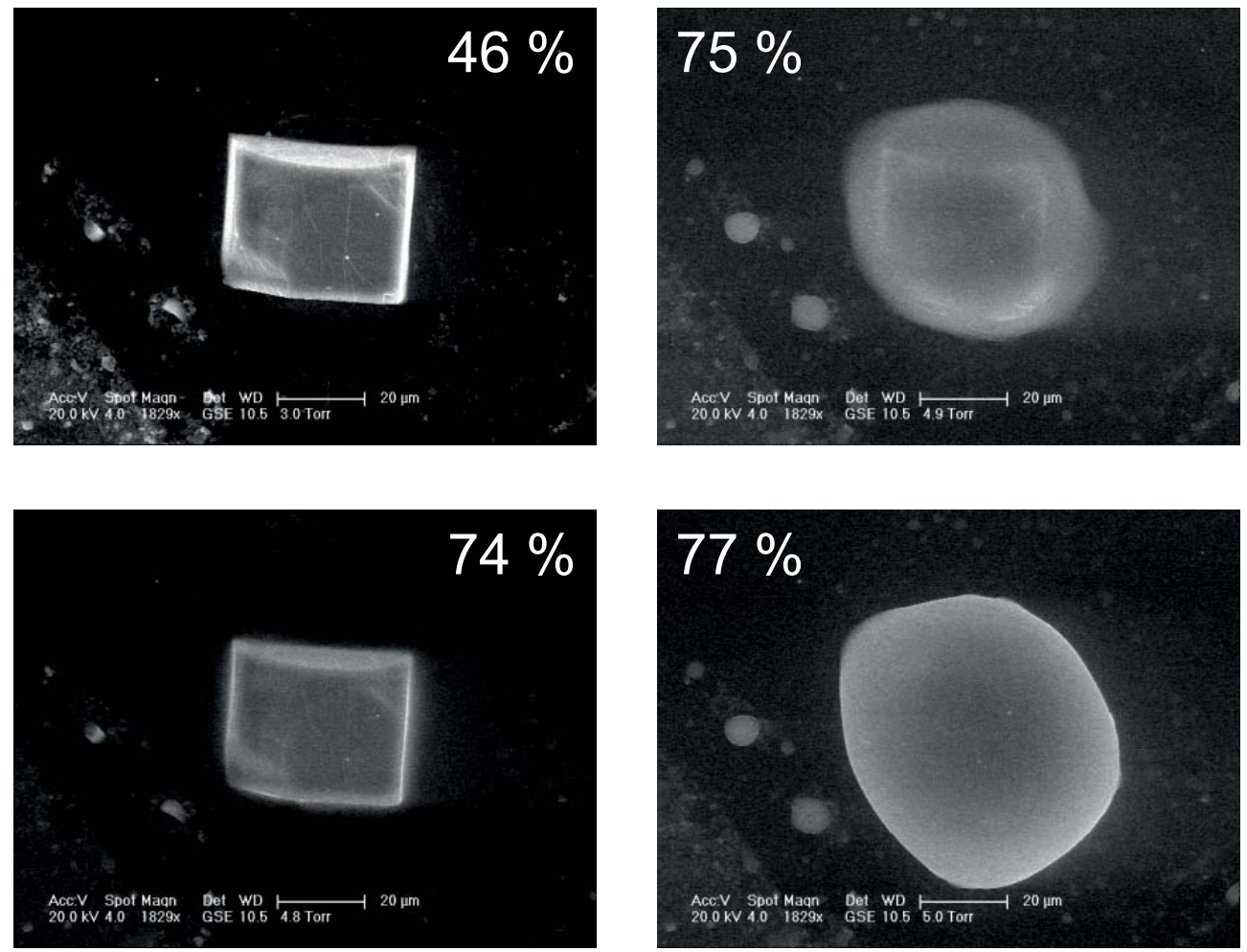

Figure 1. Sodium chloride deliquescence at $75 \% \mathrm{RH}$ observed at laboratory conditions $\left(\right.$ at $\left.4.9{ }^{\circ} \mathrm{C}\right)$ in an environmental scanning electron microscope. The dry cubic particle with sharp edges at RH of $46 \%$ becomes surrounded by a liquid sphere when RH increases to $77 \%$.

contributes $4-10 \%$ to the total number. The number size distribution is dominated by the Aitken mode. But the surface area and the volume size distribution are dominated by sea spray ( $90 \%$ of the total mass and volume) with negligible contribution of the Aitken mode, resulting in a bimodal size distribution (Wex et al., 2016, and personal communication with H. Wex, 2017). For the radiation studies as for lidar measurements the surface area and its bimodal distribution is decisive. In this study, we will focus on sea salt and its different shapes, which mainly forms the coarse or sea spray mode. The accumulation mode (later on called fine mode) consists of sea salt particles and newly formed organic particles. Sea salt is the dominant component of the coarse mode and dominates the optical properties. Therefore most of the following investigations concern the sea salt and its changes with RH.

Crystalline sodium chloride has a cubic shape, while sulfates form frequently needle-like shapes (Kandler et al., 2007). With different compounds present in sea-salt, mixed particle geometries can occur (Wise et al., 2007). With increasing RH the hygroscopic material takes up water, deliquesces, and forms a spherical solution droplet. In humid marine environments, sea salt particles are of spherical shape. Consequently sea salt exists in two shape modes, spherical and nonspherical crystalline.
The shape and thus the depolarization ratio are dependent not only on RH but also on the chemical composition and the rate at which the particles have dried (Wang et al., 2010), leading to different crystalline shapes. $\mathrm{NaCl}$ is the major component of sea salt, but other salts such as $\mathrm{Na}_{2} \mathrm{SO}_{4}$, $\mathrm{MgCl}_{2}, \mathrm{MgSO}_{4}$, and possibly some organics are part of atmospheric sea salt (Tang et al., 1997). These components prevent the perfectly cubic shape of dried sea salt (Zelenyuk et al., 2006; Zieger et al., 2017).

In Fig. 1, the deliquescence behavior of a pure sodium chloride particle is shown. It was observed with a scanning electron microscope. The cubic sodium chloride particle grows with increasing RH. Once the deliquescence point (in this case at RH of approximately $75 \%$ ) is reached, it turns into a droplet. The studies of Tang et al. (1997) found the deliquescence point for sea salt at 70-74\%, depending on the composition of the sea salt. The particles keep the spherical shape until RH decreases to 45-48 \% (Tang et al., 1997). As a result of the hysteresis effect, sea salt particles may exist in both shape modes between approximately 50 and $70 \%$ $\mathrm{RH}$, depending on their individual history. These conditions may occur quite often over the oceans and coastal areas, as illustrated by Kandler et al. (2011). The hysteresis behavior has been previously studied (Carrico et al., 2003; Wise et al., 2005). 

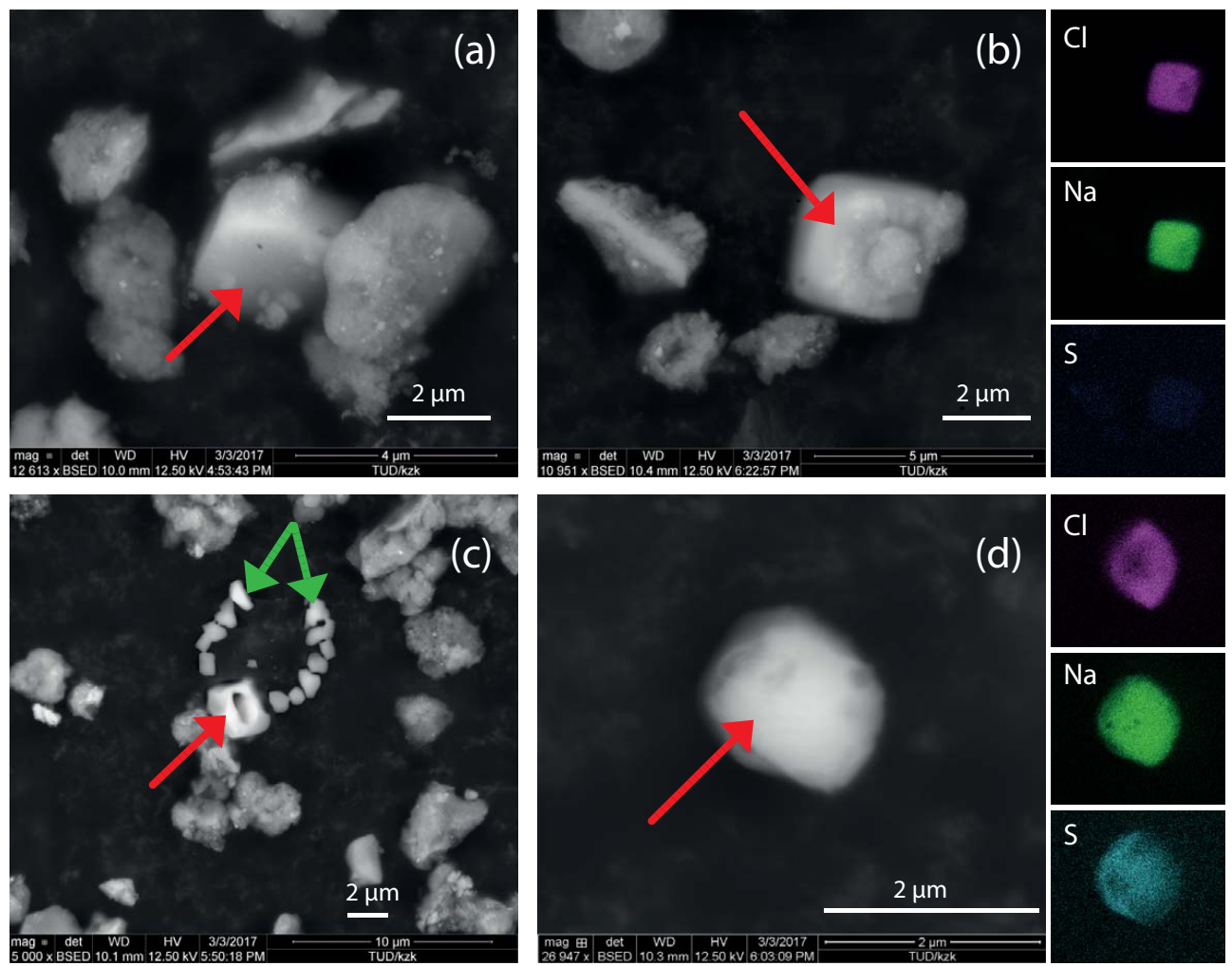

Figure 2. Images of dry atmospheric sea salt particles (red arrows) surrounded by Saharan dust particles, collected during the summer transport regime (summer 2013), whereas the later-presented profile measurements were perfomed in the absence of dust layers in February 2014. The particles were sampled aboard the Falcon research aircraft (Weinzierl et al., 2017) at different heights over Barbados on (a) 21 June, (b) 10 July, (c) 26 June and (d) 30 June 2013 during SALTRACE-1. Sampling altitude and conditions are (a) $2560 \mathrm{~m}$ a.s.1., $15^{\circ} \mathrm{C}$, $29 \% \mathrm{RH}$; (b) $3550 \mathrm{~m}$ a.s.1., $8{ }^{\circ} \mathrm{C}, 28 \% \mathrm{RH}$; (c) $3570 \mathrm{~m}$ a.s. $1 ., 7^{\circ} \mathrm{C}, 39 \% \mathrm{RH}$; (d) $3230 \mathrm{~m}$ a.s. $1 ., 8^{\circ} \mathrm{C}, 34 \% \mathrm{RH}$. For the sea salt particles in (b) and (d) the XRF images are included showing that chloride $(\mathrm{Cl})$ and sodium $(\mathrm{Na})$ are the main components. The sulfate (S) component is negligible for particle (b) but significant for particle (d), which exhibits a more spherical shape. Panel (c) shows an outline of a former droplet (green arrows), indicating a still (partial) deliquesced state during collection. The white bar in the bottom right corner indicates $2 \mu \mathrm{m}$.

Atmospheric samples of dry salt particles (Fig. 2) were collected during the SALTRACE-1 campaign (Barbados, summer 2013), whereas the case studies shown later in this publication are for pristine marine conditions observed during February 2014. The samples in Fig. 2 are taken in the dust layer (2-4 km a.s.l.), which was present during the summer months but not the winter months, when our observations of dry marine particles took place. The samples in Fig. 2 were taken in the free troposphere to ensure that the particles have been dried in airborne state to be representative for atmospheric aerosol, in contrast to wet collection followed by drying on a substrate, which might lead to substrate effects. The four dry marine particles shown in Fig. 2 were collected at RH between 28 and $39 \%$. The X-ray fluorescence spectroscopy (XRF) images reveal that particle (b) with a shape closer to a cube has a negligible contribution of sulfate, whereas particle (d) is more spherical in shape and has a larger contribution of sulfate. Also, organics of marine origin might be the reason for the more spherical shape (Laskin et al., 2012). Particle (c) shows the outline of a spherical marine aerosol droplet, so this one was probably still deliquesced at the time of collection. Overall we see that sea salt particles have a nonspherical shape that could be approximated by a cube for RH below $40 \%$. But the shape is not perfectly cubic as for pure sodium chloride (see Fig. 1). The edges of the sea salt particles dried in the atmosphere are smoother. In this publication we will call the shape of crystalline sea salt "cubic-like" to separate it from the spherical sea salt droplets under humid conditions. Compared to model results of perfectly cubic particles or pure $\mathrm{NaCl}$ salt particles investigated in the laboratory, we should measure lower depolarization ratios for dried marine aerosol in the atmosphere because of the smoothed cubic-like shape.

For spherical marine particles a low particle linear depolarization ratio (PLDR) of $0.03 \pm 0.01$ at $532 \mathrm{~nm}$ prevails (Groß et al., 2013). The range of depolarization values given in the mentioned publication is $0.01-0.11$. This indicates that not all cases classified as marine aerosol consisted of spherical sea salt particles. 
Field studies on dried marine particles are very rare. First evidence of an enhanced depolarization ratio for dry marine particles was reported by Murayama et al. (1999) based on lidar measurements in Tokyo. A clear separation from a potential dust influence was not possible. They observed a peak in the PLDR of 0.1 at $532 \mathrm{~nm}$ during sea breeze.

Sakai et al. (2000) measured RH and the depolarization ratio over Nagoya, Japan, from 1994 to 1997 with a Raman lidar. They found $532 \mathrm{~nm}$ PLDRs between 0.1 and 0.2 for $25-45 \% \mathrm{RH}$ at heights from 2 to $4 \mathrm{~km}$ in the free troposphere. Backward trajectories indicated pure marine conditions. These values are in good agreement with our observations. However, it cannot be excluded that continental particles were present as well and contributed to the light depolarization.

In a laboratory study, Sakai et al. (2010) measured the PLDR of spherical sea salt particles of $0.01 \pm 0.001$ at $532 \mathrm{~nm}$. For crystalline sea salt particles, they found a PLDR of $0.08 \pm 0.01$. Pure crystalline $\mathrm{NaCl}$ has a significantly higher depolarization ratio $(\mathrm{PLDR}=0.21 \pm 0.02$ ) than atmospheric sea salt (Sakai et al., 2010). In a laboratory study, Järvinen et al. (2016) observed pure $\mathrm{NaCl}$ particles with a depolarization ratio of 0.25 .

Additionally to the change in particle shape, the size of sea salt aerosols changes with RH. Due to water uptake sea salt aerosols are much larger under humid conditions and smaller under dry conditions. The process is known as hygroscopic growth (e.g., Zieger et al., 2013; Skupin et al., 2016). The change in optical properties (backscatter coefficient, extinction coefficient, lidar ratio) with varying $\mathrm{RH}$ can be measured with a Raman lidar. Results are shown in Sect. 4.3.

Early discrete dipole approximation (DDA) modeling attempts of spherical and cubic sea salt particles have been done by Murayama et al. (1999). For cubic particles larger than $0.8 \mu \mathrm{m}$ a PLDR of $0.08-0.22$ at $532 \mathrm{~nm}$ was predicted. David et al. (2013) used a T-matrix approach for cubic sea salt particles to model the depolarization ratio (approx. 0.16 in the visible and UV) and the lidar ratio (19 sr in UV and $20 \mathrm{sr}$ in the visible). The DDA approach for cubic particles including surface roughness (Kemppinen et al., 2015a) leads to a PLDR $0.1-0.2$ and a lidar ratio of $15-20$ sr for the particle radius equal to the wavelength (size parameter $=6$ ). Our observations will also be compared with recently performed model calculations (Sect. 5).

\section{Methods}

\subsection{The SALTRACE project}

The three SALTRACE field campaigns in 2013 and 2014 are the final observational efforts of the long-term SAMUMSALTRACE project (Heintzenberg, 2009; Ansmann et al., 2011; Weinzierl et al., 2017). During SALTRACE, we investigated the Saharan dust properties after an atmospheric travel over 5-15 days and 5000-8000 km (Weinzierl et al., 2017; Haarig et al., 2016a, 2017). In the summer seasons of 2013 and 2014 (SALTRACE-1 and SALTRACE-3 in June-July), aged dust layers were observed. To investigate aged mixtures of dust and biomass burning smoke after long-range transport, we performed an additional campaign in February-March 2014 (SALTRACE-2, winter transport regime). In February 2014 there was a period without aerosol transport from Africa, resulting in very clean marine conditions over Barbados. The SALTRACE lidar activities were complemented by shipborne lidar observations along the main Sahara dust transport route over the tropical North Atlantic in April-May 2013 (Kanitz et al., 2013; Rittmeister et al., 2017; Ansmann et al., 2017).

The ground-based remote sensing station was deployed at the Caribbean Institute for Meteorology and Hydrology $(\mathrm{CIMH})$ in Husbands, north of the capital Bridgetown at the west coast of Barbados (13.15 $\mathrm{N}, 59.62^{\circ} \mathrm{W} ; 110 \mathrm{~m}$ a.s.1.). The BERTHA (Backscatter Extinction lidar Ratio Temperature Humidity profiling Apparatus) lidar system, an AERONET sun photometer (see AERONET web page https: //aeronet.gsfc.nasa.gov/, Barbados_SALTRACE site), and a Vaisala radiosonde station (RS92 for profiling of pressure, temperature, $\mathrm{RH}$, and the vector of the horizontal wind component) were operated at the field site. A second AERONET station (Ragged Point) is located at the east coast of Barbados, approximately $20 \mathrm{~km}$ away from the CIMH.

\subsection{Triple-wavelength lidar BERTHA}

The multi-wavelength polarization Raman lidar BERTHA of the Leibniz Institute for Tropospheric Research (TROPOS) is a container-based mobile lidar system. As a unique feature, it enables the measurement of the depolarization ratio at three wavelengths $(355,532$, and $1064 \mathrm{~nm})$ simultaneously. A more detailed description of the lidar system and the polarization characteristics can be found in Haarig et al. (2017). Currently it operates as a $3+2+3$ lidar system (three backscatter coefficients, two extinction coefficients, and three depolarization ratios) with an additional water vapor channel $(407 \mathrm{~nm})$ and a high-spectral-resolution channel at $532 \mathrm{~nm}$. It has been used in a $3+3+2$ configuration in Haarig et al. (2016b). The signals are detected with a range resolution of $7.5 \mathrm{~m}$ and a time resolution of $10 \mathrm{~s}$.

The particle backscatter coefficient gives information about the aerosol layers. For particles with sizes comparable to the wavelength or larger, it is in first approximation proportional to the surface area of the bulk of particles. The extinction coefficient is determined from the transmission of the laser beam through the atmosphere. Both are calculated independently from the lidar signals via the Raman lidar method (Ansmann et al., 1992). The backscatterto-extinction ratio, also called lidar ratio, contains information about the particle size and shape, as well as about the refractive index. Therefore it is used together with the par- 
ticle depolarization ratio to classify aerosol types (Burton et al., 2012; Groß et al., 2013). The $532 \mathrm{~nm}$ channels reach full overlap at $800-1000 \mathrm{~m}$ height. The $355 \mathrm{~nm}$ channels reach full overlap at $2500-3000 \mathrm{~m}$. Therefore, they have to be overlap-corrected according to Wandinger and Ansmann (2002). The uncertainty especially of the extinction and the lidar ratio is therefore larger in the UV.

The PLDR is a measure of the depolarization caused by the scattering of linear-polarized light (defined as parallel) at atmospheric particles. It is defined as the ratio of cross-polarized to parallel-polarized light scattered back from aerosol particles. As an intensive parameter it is characteristic for a certain aerosol type. For spherical particles (droplets, wet marine particles) the PLDR is $<0.03$, whereas nonspherical particles have a higher PLDR (dust approx. 0.3 (at $532 \mathrm{~nm}$ ), ice crystals approx. 0.5; Groß et al., 2013; Haarig et al., 2017). To ensure the good quality of the depolarization measurements, a $\Delta 90^{\circ}$ calibration (Freudenthaler et al., 2009) was performed for each measurement. In the UV the systematic uncertainties are quite high $(0.01$ in the volume linear depolarization ratio). The calculation of the depolarization ratio follows Freudenthaler (2016) and is described in Haarig et al. (2017), where a detailed error estimation can be found in addition.

For the calculation of $\mathrm{RH}$, the temperature profile of the radiosonde is used. BERTHA measures the pure rotational Raman signals from nitrogen and oxygen from the $532 \mathrm{~nm}-$ emission wavelength to retrieve the temperature profile, but the uncertainty is too large to retrieve RH with a reasonable uncertainty (Mattis et al., 2002). During the SALTRACE campaign, a Vaisala RS92 radiosonde was launched for each measurement. The water vapor mixing ratio of the radiosonde is used to calibrate the water vapor mixing ratio derived by the ratio of the hydrogen $(407 \mathrm{~nm})$ and nitrogen (387 nm) Raman signal of the lidar (Whiteman et al., 1992). Due to the weak $407 \mathrm{~nm}$ signal, the technique can be used at nighttime only. By using the water vapor mixing ratio profiles of the lidar and the temperature and pressure profile of the radiosonde the temporal and vertical evolution of $\mathrm{RH}$ can be derived. The relative error of the water vapor mixing ratio caused by calibration and signal noise was $<5 \%$ at all heights within the aerosol layer (in these cases up to $2 \mathrm{~km}$ ). The temperature of the radiosonde is used for the $2 \mathrm{~h}$ of measurement, so an uncertainty of $1 \mathrm{~K}$ is reasonable. These errors lead to a maximal relative uncertainty in RH of $12 \%$, resulting in a dry RH of $40 \pm 5 \%$. A detailed error estimation for $\mathrm{RH}$ derived with a Raman lidar can be found in Mattis et al. (2002).

\subsection{The DDA model for cubic sodium chloride}

We simulate optical properties of dry sea salt particles as cubes with the refractive index $m$ of sodium chloride, provided by Eldridge and Palik (1985), i.e., with values $m=$ 1.582 at $\lambda=355 \mathrm{~nm}, m=1.549$ at $\lambda=532 \mathrm{~nm}$, and $m=$
1.531 at $\lambda=1064 \mathrm{~nm}$. The size distribution is taken from the corresponding AERONET measurement. The version 2 inversions for spherical particles are used (Holben et al., 1998).

A range of volume-equivalent particle radii up to $2 \mu \mathrm{m}$ is covered by modeling with the DDA code ADDA (Yurkin and Hoekstra, 2011) with logarithmically equidistant size steps of a factor of 1.1. We use the DDA formulation "filtered coupled dipoles" (Piller and Martin, 1998) included in ADDA, which was also used for example by Gasteiger et al. (2011), and use eight dipoles (dpl) per wavelength. To simulate random particle orientation, DDA runs for 100 orientations were carried out for each particle. The weighted distributions of particle orientations were selected according to those presented by Sloan and Womersley (2004). For each DDA run, the optical properties were averaged over 64 scattering planes rotated around the incident light direction. The single particle properties are used in a subsequent step for the calculation of the bulk optical properties (see Sect. 5).

To estimate the accuracy of these model simulations, the scattering problems were modeled in addition with settings associated with higher accuracy, i.e., one case with increased number of dipoles per wavelength $(\mathrm{dpl}=12$ instead of 8$)$ and another case where we increased the number of orientations from 100 to 225.

The uncertainty is estimated for the lidar ratio of single randomly oriented particles to be on the order of $\pm 10 \%$ and for the linear depolarization ratios about \pm 0.02 . A similar uncertainty is estimated for the final optical properties of the bulk sea salt aerosol. The estimate for the bulk properties is based on the uncertainty being, on the one hand, reduced by averaging over the size distribution or, on the other hand, increased due to the fact that the assumed size distribution, particle shape, and refractive index are given with an uncertainty.

\section{Observations}

The island of Barbados is ideal to observe pure marine conditions. It is the eastern-most island of the Caribbean and located in the trade wind zone with predominant wind direction from the east. In winter, the inner tropical convergence zone is shifted to the Southern Hemisphere, so the air masses originating from the African continent are transported to South America (e.g., Baars et al., 2011), leaving the Caribbean under marine influence.

The MAL extends up to the strong trade wind inversion at around $2 \mathrm{~km}$ height. The MAL is defined by the predominance of marine aerosol. It includes the convective MBL and another residual layer of marine particles. The dust removal process in the MAL is very efficient as shown in Rittmeister et al. (2017). As there was no dust or other continental aerosol in the free troposphere above the MAL, it is very unlikely that dust reached Barbados during February 2014. 


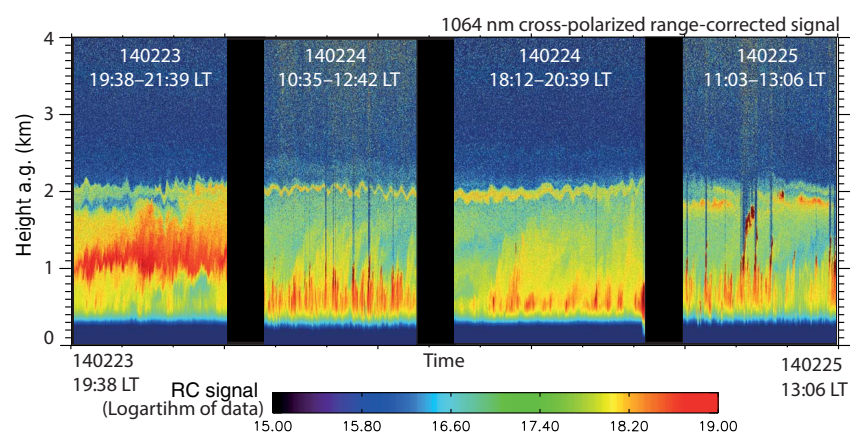

Figure 3. Three days of lidar observations (23-25 February 2014) of layers with dried marine particles in the marine aerosol layer (MAL). On 23 February (left panel), a vertically extended layer of dried sea salt particles (red area) occurred on top of the convective boundary layer. A continuously 100-200 m thick layer with dried marine particles (yellow layer at MAL top) was present over the whole day on 24 February 2014; this layer was still present on 25 February. The convectively active MBL reaches about $1 \mathrm{~km}$ on all 3 days and permanently pushed marine aerosol upward. The shown range-corrected $1064 \mathrm{~nm}$ backscatter signal (cross-polarized channel, $10 \mathrm{~s}$ temporal, $7.5 \mathrm{~m}$ vertical resolution) is most sensitive to enhanced light depolarization produced by dry marine aerosol. LT: local time.

During the SALTRACE-2 campaign (16 February8 March 2014), a layer of enhanced cross-polarized signal was observed for several days. Figure 3 shows the period from 23 to 25 February 2014. A strong decrease in RH from 80 to less than $10 \%$ at the trade wind inversion height (MAL top) was continuously observed between 20 and 25 February 2014. The enhanced depolarization ratio corresponding to this RH decrease was found to be between 0.04 and 0.12 (at $532 \mathrm{~nm}$ ). The two night measurements of 23 and 24 February 2014 will be discussed in the following section to demonstrate how the decrease in RH leads to an increase of the linear depolarization ratio due to the change in the shape properties of the sea salt particles. Firstly, the observations during the two night measurements will be described. Then, the changes in shape and size with RH will be discussed by using the PLDR and the particle backscatter coefficient, respectively.

\subsection{Profile measurements of backscatter, depolarization, lidar ratio, and $\mathrm{RH}$}

An overview of the observations on 23 and 24 February 2014 is given in Figs. 4 and 5. On 23 February 2014, the MAL was not well mixed. RH decreased steadily from $80 \%$ at $250 \mathrm{~m}$ height to $35 \%$ at $1000 \mathrm{~m}$ height. Above the $1000 \mathrm{~m}$ height level, RH increased again up to $80 \%$ at $1800 \mathrm{~m}$ height. Then a fast decrease of RH (from 80 to less than $10 \%$ ) occurred at the trade wind inversion height between 1850 and $2150 \mathrm{~m}$ height. The strong decrease of RH at MAL top was observed for most of the measurements under clean marine conditions

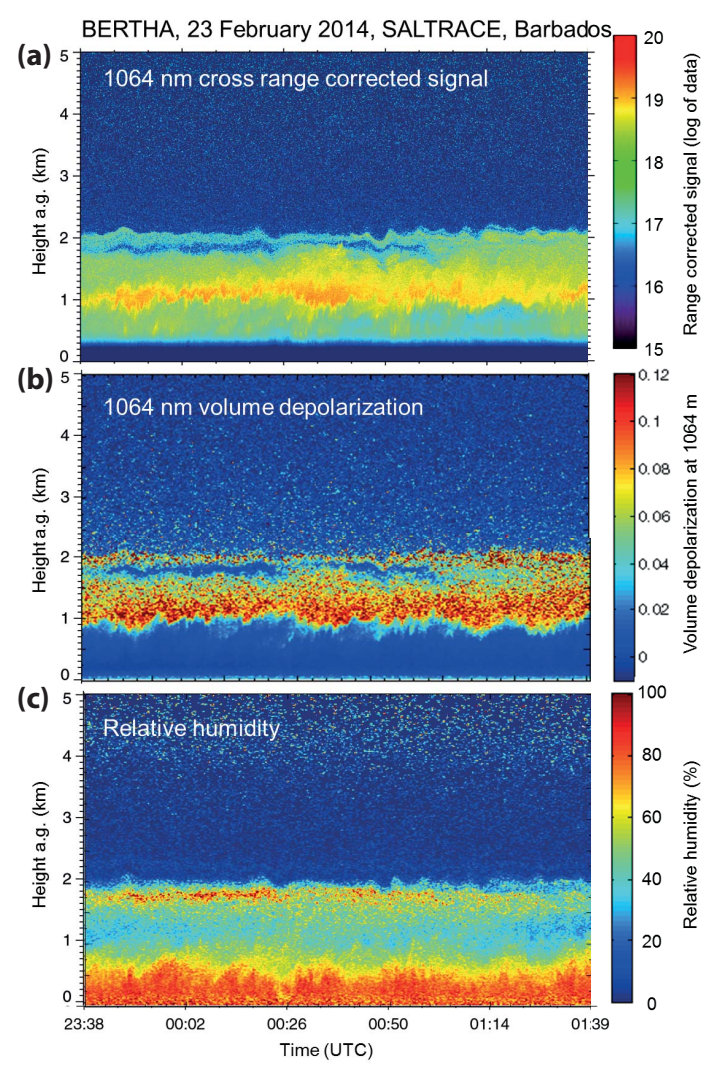

Figure 4. Marine aerosol layer (MAL) over Barbados on 23 February 2014, 19:38-21:39 local time, with the cloud-free MBL reaching to $0.8-1 \mathrm{~km}$ height (indicated by a low depolarization ratio and high RH) and an extended layer between about 1 and $2.1 \mathrm{~km}$ height with dried marine sea salt particles causing enhanced light depolarization (b yellow-red areas) at low RH of $<50 \%$ (c, bluish areas). The cross-polarized $1064 \mathrm{~nm}$ signal (a $10 \mathrm{~s}$ temporal, $7.5 \mathrm{~m}$ vertical resolution) highlights the layer with dried marine particles (yellow areas). Panels (b) and (c) are based on depolarization ratio and $\mathrm{RH}$ profile values averaged over $30 \mathrm{~s}$ and vertically smoothed over $22 \mathrm{~m}$ (b) and $52 \mathrm{~m} \mathrm{(c).}$

in February 2014. The time-height display of RH is shown in Fig. 4c. The increased signal in the cross-polarized channel and the volume depolarization ratio at $1064 \mathrm{~nm}$ are shown in Fig. 4a and b. In parts with low RH, mostly between 1000 and $1600 \mathrm{~m}$, the volume depolarization ratio is high, indicating nonspherical particles.

On 24 February 2014, only a thin layer of dried marine particles was observed. The MAL reached up to $2 \mathrm{~km}$ height (Fig. 5). The feature of interest is the enhanced $1064 \mathrm{~nm}$ cross-polarized signal in the upper $200 \mathrm{~m}$ of the aerosol layer. The radiosonde launched at 23:07 UTC (19:07 local time; LT) shows a strong temperature inversion of $4 \mathrm{~K}$ within $200 \mathrm{~m}$ around $2000 \mathrm{~m}$ height (trade wind inversion height). RH was about 65 to $80 \%$ throughout the MAL and decreased to values of $5 \% 200 \mathrm{~m}$ above the MAL. RH (Fig. 5c) indicates that the environmental conditions remained unchanged 


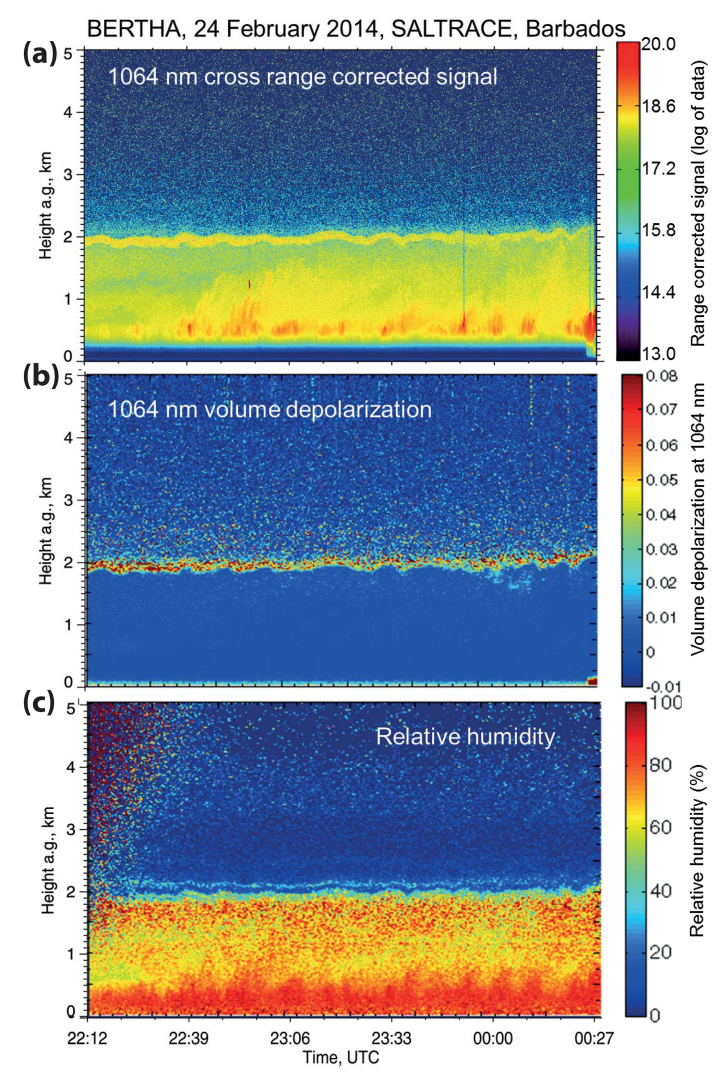

Figure 5. Same as Fig. 4, except for 24 February 2014, 18:1220:27 local time. The MAL top is again close to $2 \mathrm{~km}$ height. The convective MBL reaches to about $800 \mathrm{~m}$ height and permanently pushes sea salt particles into the upper part of the MAL. RH is high throughout the MAL (and thus depolarization ratio caused by spherical, wet marine particles is low). Only at MAL top do dried marine particles cause a thin layer of enhanced cross-polarized signal (a $10 \mathrm{~s}$ temporal, $7.5 \mathrm{~m}$ vertical resolution) and depolarization ratio (b). Daytime noise is visible in the $\mathrm{RH}$ (c) in the first half hour after sunset at 22:06 UTC. Panels (b) and (c) are based on the depolarization ratio and $\mathrm{RH}$ profile values averaged over $30 \mathrm{~s}$ and vertically smoothed over $22 \mathrm{~m}$ (b) and $52 \mathrm{~m}$ (c).

during the $2 \mathrm{~h}$ average (18:11-20:20LT). Marine particles lost their spherical shape at the top of the marine aerosol layer (efflorescence). This caused an enhanced depolarization ratio, as can be seen in Fig. $5 \mathrm{~b}$.

For the further discussion it is important to show that predominately marine aerosol particles were present over Barbados in the lowest $2000 \mathrm{~m}$. HYSPLIT backward trajectories (Stein et al., 2015; HYSPLIT, 2017) and AERONET (Holben et al., 1998; AERONET, 2017) observations are used to demonstrate that pure marine conditions were given.

The ensemble of 7-day backward trajectories for 23 February (Fig. 6a) indicates marine sources over the Atlantic for the air mass, with only a rather small chance of aerosol uptake over Western Sahara. On 24 February the ensemble
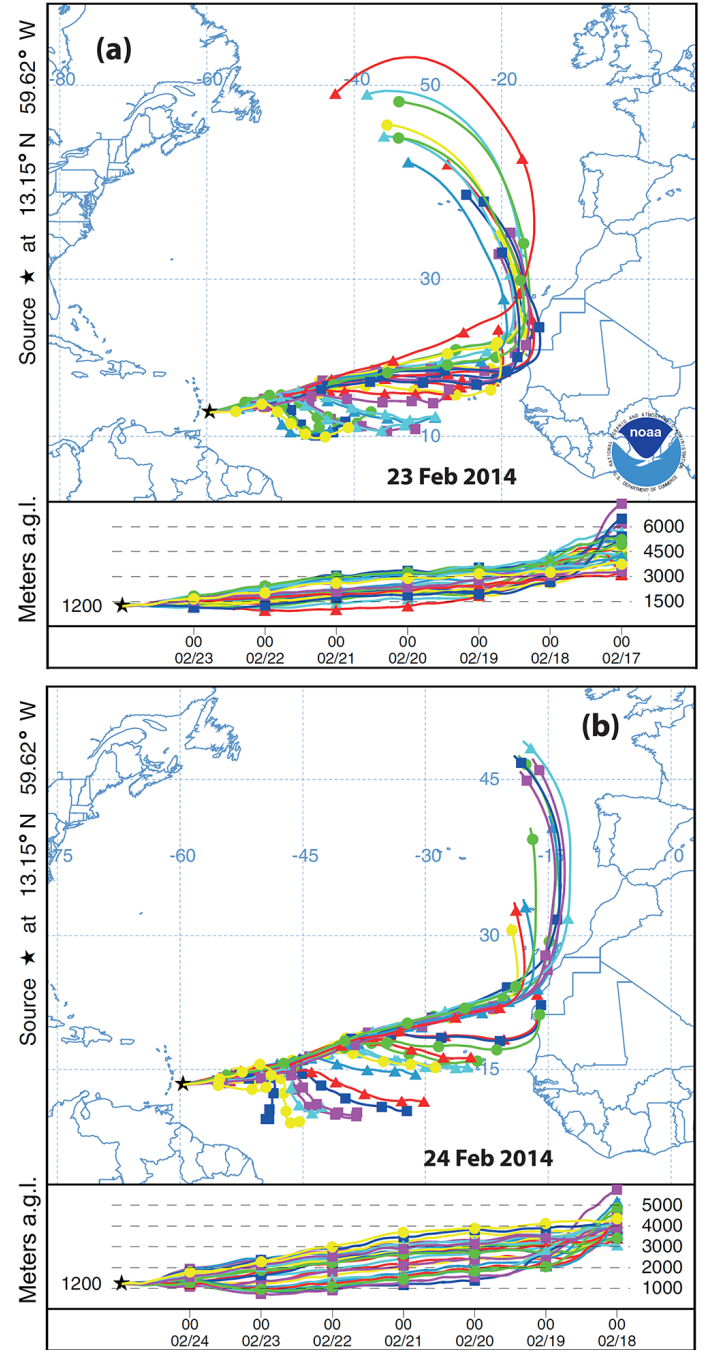

Figure 6. Ensemble of 7-day backward trajectories (HYSPLIT, 2017) for (a) 24 February 2014, 00:00 UTC, and (b) for 24 February 2014, 23:00 UTC, arriving at $1200 \mathrm{~m}$ over Barbados.

of 7-day backward trajectories (Fig. 6b) shows only marine aerosol sources for the MAL.

In Fig. 6, only one height level $(1200 \mathrm{~m})$ is considered for the MAL. A more sophisticated analysis of the ensembles of trajectories at different heights is shown in Fig. 7. To estimate the contributions of marine and continental aerosol sources to the observed air masses, ensembles of HYSPLIT backward trajectories (Stein et al., 2015) were calculated in vertical steps of $500 \mathrm{~m}$. Each ensemble consists of 27 single trajectories which are initialized with a small spatial offset. An air parcel is assumed to get laden with aerosols over a given marine or continental source region when the parcel is at heights below $2 \mathrm{~km}$ above this region. The colors in Fig. 7 indicate the contribution of different land cover categories, taken from MODIS (Friedl et al., 2002). 


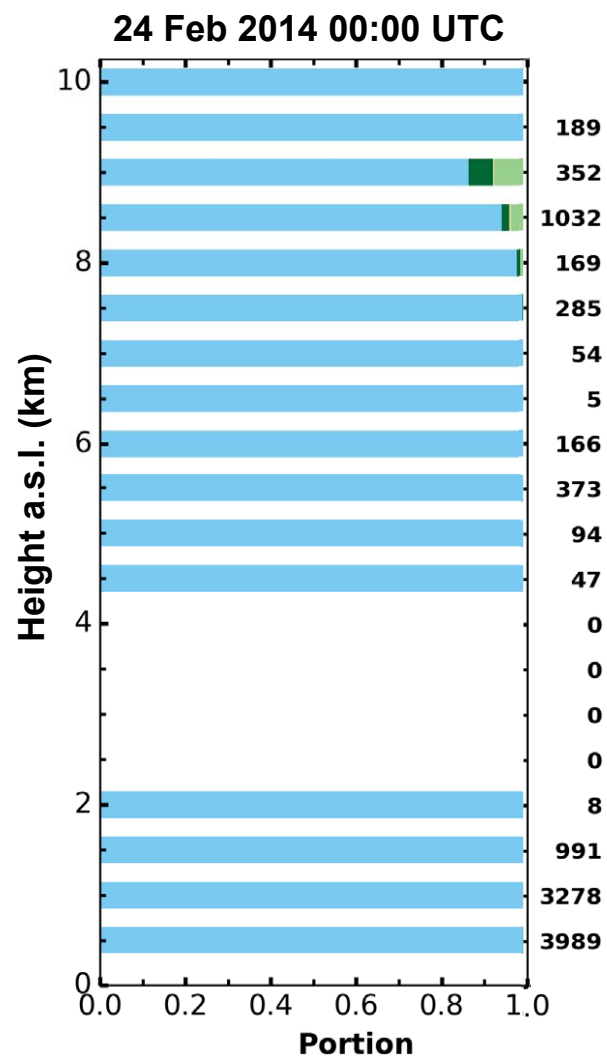

Figure 7. Relative residence time of the air masses over ground within the 10 days prior to their arrival over Barbados (24 February 2014, 00:00 UTC). For each height level $(500 \mathrm{~m})$ an ensemble of 27 HYSPLIT trajectories was calculated. The numbers on the right-hand side indicate the total amount of hours that the ensemble of 10-day backward trajectories at each height level spend close to the ground (below $2 \mathrm{~km}$ height) and could be possibly laden with aerosols. The color bar indicates the portion of different surface areas, where blue stands for ocean and green for different types of continental land cover (forest, grass, etc.). The land cover is taken from MODIS. Between 2.5 and $4.0 \mathrm{~km}$ height, the trajectories did not come close to the ground. The air masses in the MAL (up to $2 \mathrm{~km}$ height) are purely marine. The same result was found on 25 February 2014, 00:00 UTC (not shown).

Considering the ensembles of trajectories at different heights below $2000 \mathrm{~m}$ for both nights (Fig. 7, only the night of 23 February shown), none of the 10-day back trajectories crossed a continental site at heights below $2 \mathrm{~km}$. This analysis clearly indicates that our lidar observations were performed at pure marine aerosol conditions.

The measurements of the AERONET sun photometers at Ragged Point and at the field site (Barbados_SALTRACE) are shown in Fig. 8 (Holben et al., 1998; AERONET, 2017). The aerosol optical thickness (AOT at $500 \mathrm{~nm}$ ) is low and accumulates around 0.05 . Very low Ångström exponents (AE) were found and indicate the dominance of coarse mode particles. In our cases the $\mathrm{AE}$ at the closest AERONET ob-

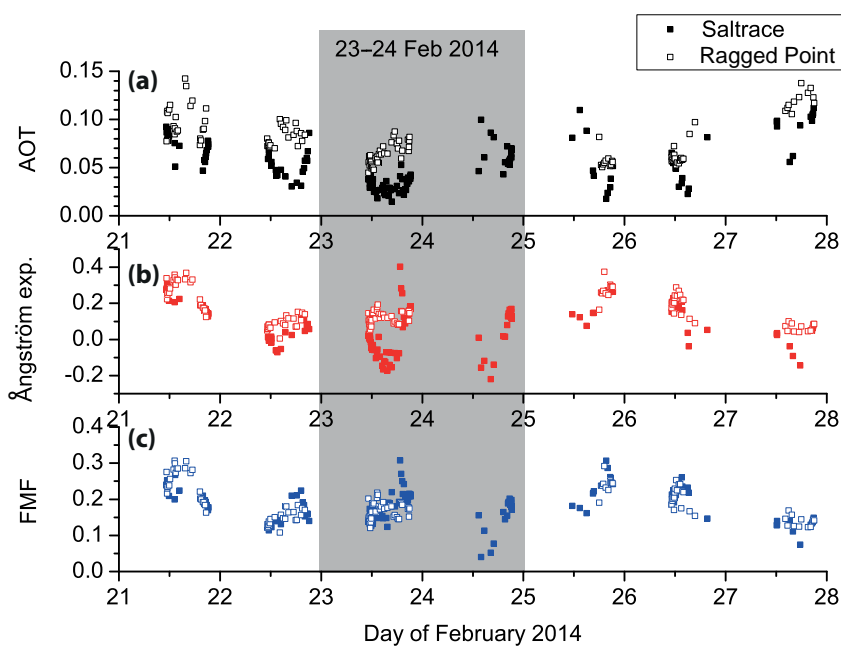

Figure 8. AERONET retrieval products for 21-28 February 2014: (a) Aerosol optical thickness (AOT) at $500 \mathrm{~nm}$; (b) Ångström exponent (440-870 nm); (c) fine mode fraction (FMF). AERONET level 2.0 data from Ragged Point and Barbados_SALTRACE are shown. The gray area highlights the time period of lidar observations discussed in this section.

servations (after 20:00 UTC) are between 0.1 and 0.2. The fine mode fraction (FMF) is also typical for coarse-modedominated particle ensembles.

The transport of dust over $5000-8000 \mathrm{~km}$ below the trade wind inversion is extremely unlikely. The dust particles will get lost due to turbulent downward mixing or gravitational sedimentation or wet deposition. The observations of Rittmeister et al. (2017) support the conceptual model (Karyampudi et al., 1999), which implies a very efficient removal of dust from the MAL. Dust is transported over long distances in the Saharan air layer (SAL) above the trade wind inversion (above the MAL). But in late February 2014, the SAL was not present over the MAL. In conclusion, all air mass back trajectory studies and the AERONET observations indicate clean marine conditions over Barbados during 23 and 24 February 2014.

The vertical profiles of the particle backscatter coefficient and the PLDR for the three wavelengths $(355,532$, and $1064 \mathrm{~nm}$ ) of the BERTHA lidar system are shown in Figs. 9 and 10. A good agreement is achieved between RH measured with the radiosonde and the $30 \mathrm{~min}(2 \mathrm{~h})$ mean $\mathrm{RH}$ profile retrieved from the lidar observations. The profile of $\mathrm{RH}$ in combination with the profiles of the backscatter coefficient and the PLDR indicate the sensitive changes in the marine optical properties with changing $\mathrm{RH}$. The crystallization point for sea salt of 45-48\% RH (Tang et al., 1997) is marked with a dashed line. The depolarization ratio increases strongly when RH drops below this point. The change of the backscatter coefficient with RH is less pronounced.

When RH decreases below the crystallization point at $810 \mathrm{~m}$ height, the PLDR starts to increase and takes its max- 

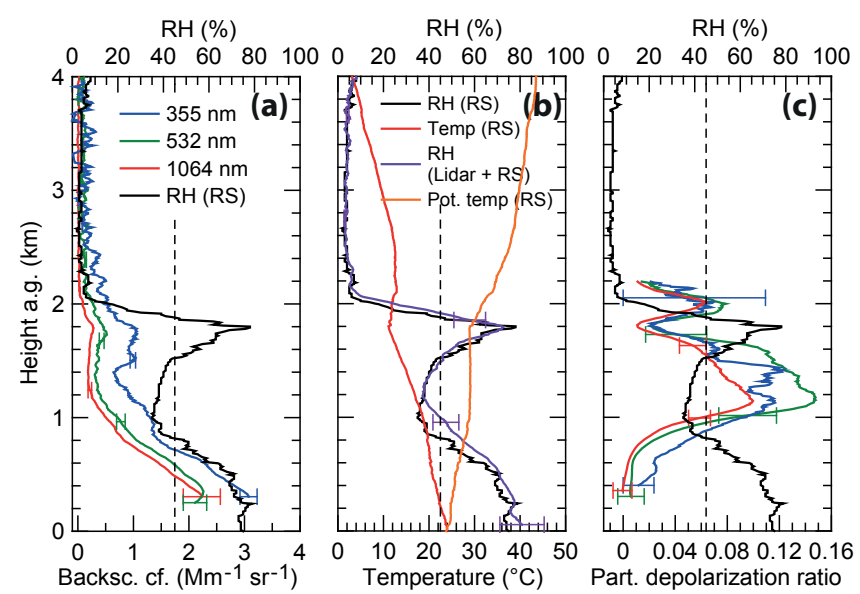

Figure 9. Thirty-minute mean profiles of particle backscatter coefficient (a) and particle linear depolarization ratio (c) at three wavelengths together with radiosonde RH (indicating the MAL up to $2 \mathrm{~km}$ height). The lidar observation was performed on 23 February 2014, 19:45-20:15 local time (23:45-00:15 UTC). The atmospheric variability was low during the signal averaging period (Fig. 4). Panel (b) shows the potential temperature ( $T_{\text {pot }}$, radiosonde, launch at 00:00 UTC) and RH from radiosonde and from lidar (30 min average). Note the sharp drop in $\mathrm{RH}$ from $>70 \%$ (at $1850 \mathrm{~m}$ height) to $<10 \%$ (at $2100 \mathrm{~m}$ height). The dashed line marks the sea salt efflorescence point ( $45 \% \mathrm{RH})$. Error bars indicate the lidar retrieval uncertainty. The vertical smoothing window length is $50 \mathrm{~m}$ for the backscatter and RH (lidar) and $100 \mathrm{~m}$ for the depolarization ratio.

imum of $0.148 \pm 0.035$ at $532 \mathrm{~nm}$ at around $1150 \mathrm{~m}$ height. RH increases again between 1000 and $1800 \mathrm{~m}$ and reaches $70-74 \%$ (deliquescence point of sea salt) at $1780 \mathrm{~m}$. The PLDR decreases below $0.02(532 \mathrm{~nm})$ at this height. This behavior will be further discussed in Sect. 4.2. The second decrease in $\mathrm{RH}$ at the trade wind inversion height leads to a less pronounced peak in the PLDR (value \pm systematic uncertainty) of $0.069 \pm 0.161$ at $355 \mathrm{~nm}, 0.079 \pm 0.036$ at $532 \mathrm{~nm}$, and $0.063 \pm 0.018$ at $1064 \mathrm{~nm}$ around $2000 \mathrm{~m}$ height.

In the $2 \mathrm{~h}$ mean profiles of the 24 February 2014 (Fig. 10, $100 \mathrm{~m}$ vertical smoothing is applied), maximum PLDRs of $0.055 \pm 0.109(355 \mathrm{~nm}), 0.068 \pm 0.035(532 \mathrm{~nm})$, and $0.038 \pm 0.010(1064 \mathrm{~nm})$ are reached in the thin layer of dried marine aerosol at MAL top. In the humid MAL below, the PLDR is below 0.02 and thus clearly indicates the spherical shape of the sea salt particles.

The Raman lidar method allows us to derive the extinction coefficient independently of the backscatter coefficient and therefore to measure the lidar ratio, shown in Fig. 11. In the humid MAL on 24 February the lidar ratio is $19 \pm 5 \mathrm{sr}$ at $355 \mathrm{~nm}$ and $23 \pm 2 \mathrm{sr}$ at $532 \mathrm{~nm}$, which is typical for spherical marine particles (Müller et al., 2007; Groß et al., 2013; Rittmeister et al., 2017). For the aerosol layer with dried marine particles on 23 February (1000-1600 m height), we obtained a lidar ratio of $27 \pm 6 \mathrm{sr}$ (at $355 \mathrm{~nm}$ ) and $25 \pm 3 \mathrm{sr}$ (at $532 \mathrm{~nm}$ ) for the cubic-like sea salt particles. The increase in
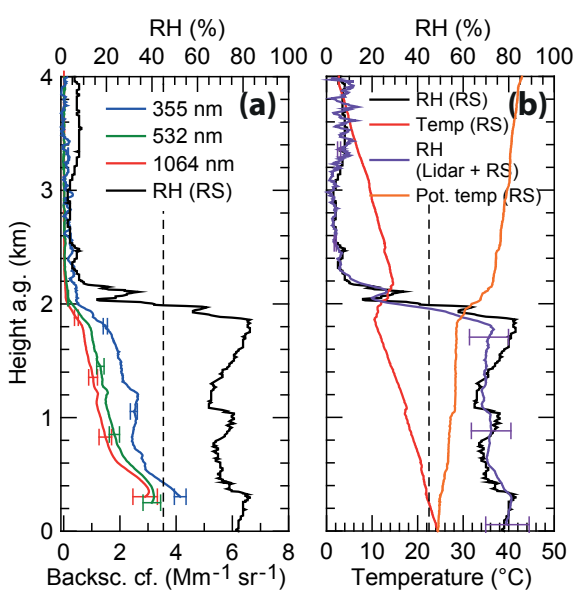

$\mathrm{RH}(\%)$

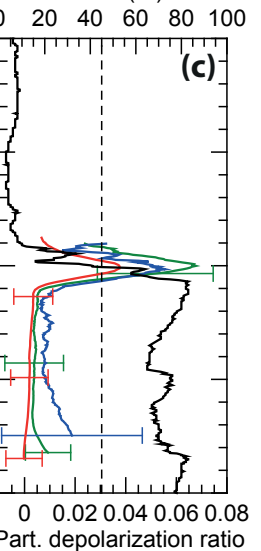

Figure 10. Same as Figure 9 but for 24 February 2014, 18:12-20:20 local time (22:12-00:20 UTC). In panel (b), the respective $2 \mathrm{~h} \mathrm{RH}$ profile (from lidar) is shown together with the radiosonde profiles (launch at 23:07 UTC). The MAL was entirely humid on this day.

the lidar ratio may be explained by the reduction in particle size, as the sidewards scattering (extinction without absorption) increases for smaller particles. The results are summarized in Table 1 for dry and humid conditions. There, the results of our modeling efforts presented in Sect. 5 are shown as well for comparison. For cubic sea salt particles we simulated lidar ratios of 13,20 , and $36 \mathrm{sr}$ at 355,532 , and $1064 \mathrm{~nm}$, respectively. David et al. (2013) simulated with the T-matrix approach a lidar ratio of $19 \mathrm{sr}$ and $20 \mathrm{sr}$ at 355 and $532 \mathrm{~nm}$ for cubic sea salt particles.

\subsection{Observation of the phase transition in the depolarization ratio}

A unique opportunity is provided to study the relation between marine particle shape and RH with high temporal $(5 \mathrm{~min})$ and vertical $(50 \mathrm{~m})$ resolution under atmospheric conditions. The correlation between PLDR and RH for 23 February 2014 is shown in Fig. 12d-f. Only the decrease in RH is depicted here (375-1100 m height range). The crystallization point (45-48\% RH) is more important than the deliquescence point $(70-74 \% \mathrm{RH})$ when the drying process is highlighted. Inorganic sea salt has multiple crystallization points due to its complex composition (Tang et al., 1997; Zieger et al., 2017). The drying follows the upper branch of the hysteresis as fully deliquesced sea salt particles are drying. From 80 to $50 \%$ RH the PLDR increases slightly with decreasing RH but remains $\leq 0.02$ $(532,1064 \mathrm{~nm})$ and $\leq 0.03(355 \mathrm{~nm}$, due to higher noise level). This observation is in line with typical depolarization values for marine aerosol as used in aerosol classification schemes (e.g., Groß et al., 2013). At around 50\% RH the PLDR increases drastically indicating a significant change in particle shape from spherical to cubic-like shape. 


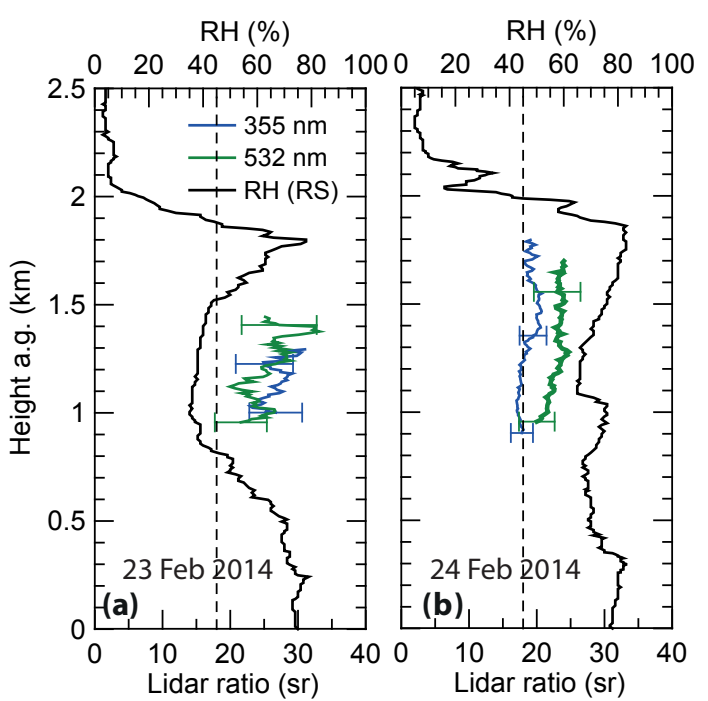

Figure 11. Two-hour mean profiles of the lidar ratio for the 23 February (a $500 \mathrm{~m}$ vertical smoothing) and the 24 February 2014 (b $750 \mathrm{~m}$ vertical smoothing): 532 (green line) without overlap correction, full overlap at 800-1000 m, and 355 (blue line) with overlap correction. The RH profile of the radiosonde (black line) indicates the different layers.

The PLDR reaches maximum values (with systematic uncertainty) of about $0.12 \pm 0.08(355 \mathrm{~nm}), 0.15 \pm 0.03(532 \mathrm{~nm})$, and $0.10 \pm 0.01$ (at $1064 \mathrm{~nm}$ ) at RH of around $40 \%$. After the phase transition from spherical sea salt droplets to cubiclike sea salt crystals, the depolarization ratio remains at the high level even for RH close to $35 \%$. A further drying was not observed in the atmosphere yet, so we can only speculate about the depolarization ratio for sea salt particles under very dry conditions ( $0-35 \% \mathrm{RH})$.

Furthermore, the measurement of 23 February 2014 contains information about the humidification process. Between 1100 and $1800 \mathrm{~m}$ height RH is increasing again up to $80 \%$. Figure 13 contrasts the PLDR dependence on RH during humidification and drying. The sea salt keeps a cubic-like shape, causing an enhanced depolarization ratio even at $\mathrm{RH}$ close to $60 \%$. The depolarization values then slowly decrease to values below 0.02 typical for spherical sea salt particles (above around $65-70 \% \mathrm{RH}$ ). The hysteresis effect leads to the existence of both shape modes between 50 and $70 \% \mathrm{RH}$.

\subsection{Scattering enhancement factors of pure marine aerosol}

Beside the change in particle shape, the particle size is changing with decreasing RH. Sea salt particles grow by water uptake when RH increases. The particle backscatter coefficient is proportional to the surface area of the scattering particles and therefore a good indicator for particle growth. The AE (not shown) increase monotonically between 1.0 and $1.5 \mathrm{~km}$
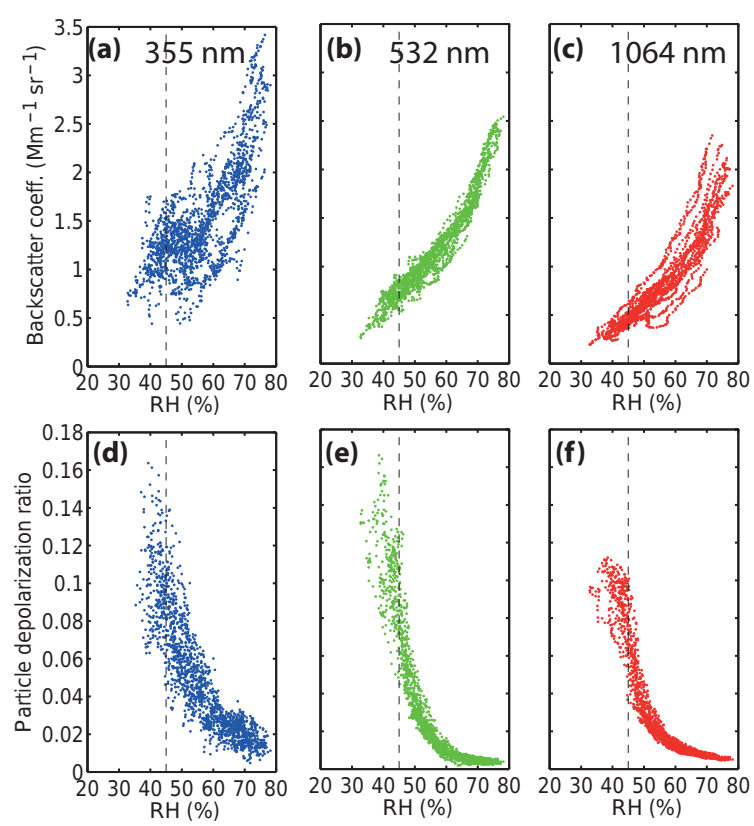

Figure 12. Correlation of the particle backscatter coefficient (a-c) and particle linear depolarization ratio (d-f) with RH for the three wavelengths 355,532 , and $1064 \mathrm{~nm}$. The BERTHA measurements of 23 February 2014, 23:38-01:08 UTC, at 375-1100 m height are used ( $5 \mathrm{~min}$ temporal and $50 \mathrm{~m}$ vertical resolution). The dashed line marks the sea salt efflorescence point ( $45 \% \mathrm{RH})$.

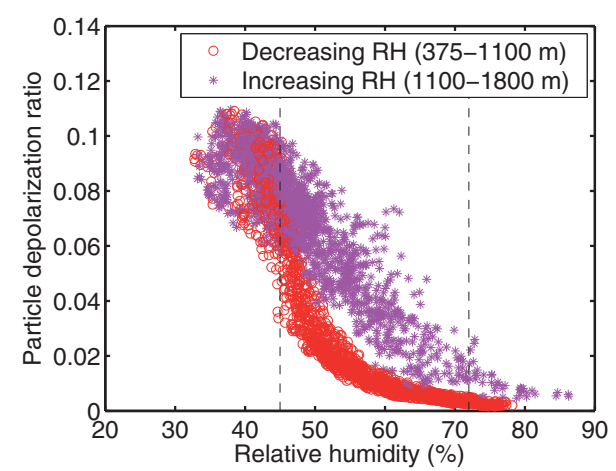

Figure 13. Correlation of the PLDR at $1064 \mathrm{~nm}$ and RH for the same settings as in Fig. 12, but for a different height interval (375$1800 \mathrm{~m}$ ). Above $1100 \mathrm{~m}$ (purple stars) RH increases again, up to $80 \%$, as can be seen in Fig. 9. The depolarization ratio decreases with increasing $\mathrm{RH}$ but keeps higher values. The hysteresis effect between crystallization (45-48\% RH, dashed line) and deliquescence (70-74\% RH, dashed line) can be seen.

(extinction AE, lower limit due to overlap) and between 0.4 and $1.5 \mathrm{~km}$ (backscatter 532 to $1064 \mathrm{~nm} \mathrm{AE).} \mathrm{This} \mathrm{is} \mathrm{a} \mathrm{clear}$ indication for the decrease in particles size. In Fig. 12a-c the particle backscatter coefficient $\beta$ is plotted against RH for the height interval $375-1100 \mathrm{~m}$ for the three wavelengths $(\lambda=355,532,1064 \mathrm{~nm})$, measured with a vertical resolution of $50 \mathrm{~m}$ and temporal resolution of $5 \mathrm{~min}$ on 23 Febru- 
Table 1. Measurement and simulation of the lidar ratio and the particle linear depolarization ratio for wet and dry marine particles. The depolarization ratio ( $100 \mathrm{~m}$ vertical smoothing) and the lidar ratio $(500 \mathrm{~m}$ vertical smoothing) are measured at the indicated height, to which the given RH value belongs. The systematic uncertainties are given. The lidar ratio at $1064 \mathrm{~nm}$ could not be measured in this configuration of BERTHA (see Haarig et al., 2016b). For the DDA simulation of spherical and cubic particles the AERONET size distribution (SD) from Ragged Point at 12:31 UTC on 23 February 2014 is taken. The effective radius was $1.033 \mu \mathrm{m}$. In order to mimic dry marine particles, the radius of the size distribution was divided by a factor of 2 . For the wet marine particles a mixture of $7: 1$ parts of water to salt was used. The model uncertainties are described in Sect. 3.3. The T-matrix results for a typical size distribution of sea salt (O'Dowd et al., 1997) are taken from David et al. (2013). The modeled uncertainties are extremely small, less than $1 \mathrm{sr}$ for the lidar ratio.

\begin{tabular}{|c|c|c|c|c|c|c|c|}
\hline \multirow[b]{2}{*}{ Wavelength (nm) } & \multicolumn{3}{|c|}{ Lidar ratio (sr) } & \multicolumn{3}{|c|}{ Particle depolarization ratio $(\%)$} & \multirow[t]{2}{*}{ Comments } \\
\hline & 355 & 532 & 1064 & 355 & 532 & 1064 & \\
\hline \multicolumn{8}{|l|}{ Measurement } \\
\hline Wet $(\mathrm{RH}=80 \%)$ & $19 \pm 5$ & $23 \pm 2$ & - & $\leq 3.0$ & $\leq 2.0$ & $\leq 2.0$ & 2014-02-24 22:11-00:21 UTC, $<1800 \mathrm{~m}$ \\
\hline Dry $(\mathrm{RH}=40 \%)$ & $27 \pm 6$ & $25 \pm 3$ & - & $11.5 \pm 8.2$ & $14.8 \pm 3.5$ & $9.9 \pm 1.1$ & 2014-02-23 23:38-01:08 UTC, $1150 \mathrm{~m}$ \\
\hline \multicolumn{8}{|l|}{ Simulation } \\
\hline Wet (spherical) & $22 \pm 2$ & $27 \pm 3$ & $35 \pm 4$ & 0 & 0 & 0 & Mie, AERONET SD 2014-02-23 \\
\hline \multirow[t]{3}{*}{ Dry (cubic) } & $10 \pm 1$ & $16 \pm 2$ & $31 \pm 3$ & $8.8 \pm 2.0$ & $11.9 \pm 2.0$ & $14.2 \pm 2.0$ & DDA, AERONET SD 2014-02-23 \\
\hline & $13 \pm 1$ & $20 \pm 2$ & $36 \pm 4$ & $10.8 \pm 2.0$ & $12.8 \pm 2.0$ & $12.0 \pm 2.0$ & DDA, AERONET SD 2014-02-23, radius/2 \\
\hline & 19 & 20 & - & $15.9 \pm 0.1$ & $16.2 \pm 0.1$ & - & T-matrix, sea salt SD*, David et al. (2013) \\
\hline
\end{tabular}

* Size distribution from O’Dowd et al. (1997)

ary 2014. The backscatter enhancement factor $f_{\beta}(\mathrm{RH}, \lambda)$ is calculated:

$f_{\beta}(\mathrm{RH}, \lambda)=\frac{\beta(\mathrm{RH}, \lambda)}{\beta(40 \%, \lambda)}$.

Under atmospheric conditions it is hardly possible to observe completely dry marine particles $(\mathrm{RH}<10 \%)$. Therefore the backscatter coefficient at $40 \% \mathrm{RH}$ was chosen as reference value to normalize the data, as is common in the literature (see discussion in Skupin et al., 2016). Lower values than $35 \%$ RH were not accessible under the measurement conditions over Barbados. RH of $40 \%$ is below the crystallization point, so sea salt particles should not be affected by the hysteresis any more; i.e., significant shrinking at further decreasing RH should not be the case. Nevertheless, the sea salt particles are not completely dry at $40 \%$ RH. Laboratory studies (Tang et al., 1997; Zieger et al., 2017) show an increase of the enhancement factor of $20-30 \%$ between $0 \% \mathrm{RH}(f=1.0)$ and $40 \%$ RH $(f \approx 1.2-1.3)$. Other lidar-based studies used $40 \%$ or $60 \%$ as reference RH (Granados-Muñoz et al., 2015; Veselovskii et al., 2009) since it was the lowest value found in their atmospheric measurements. In the following we will use the expression "dry" when we refer to RH of $40 \%$, keeping in mind that sea salt is not completely dry but below the crystallization point.

To parameterize the backscatter enhancement factor, we follow Kasten (1969) and Hänel (1976):

$f_{\beta}(\mathrm{RH}, \lambda)=A *(1-\mathrm{RH} / 100)^{-\gamma}$.

The parameter $A$ gives the extrapolated value at $0 \% \mathrm{RH}$ and the exponent $\gamma$ describes the hygroscopic behavior of the particles. This parameterization (sometimes with $A=1$ for starting at $0 \% \mathrm{RH}$ ) has been used by various investigators (Carrico et al., 2003; Veselovskii et al., 2009; Skupin et al., 2016). Retrieving values of $A<1$ (Table 2) for the upper branch of the hysteresis clearly indicates that the reference $\mathrm{RH}$ of $40 \% \mathrm{RH}$ for the backscatter coefficient is too high, so that the sea salt particles are not completely dry.

The backscatter enhancement factors are shown in Fig. 14 with the parameterization according to Eq. (2). The fit is shown on a linear scale (Fig. 14a) and on a log-log scale (Fig. 14b). The log-log plot shows that the parameterization does not hold for the lowest RH. The fit parameters are listed in Table 2. RH has fairly reached $80 \%$ in the used height interval. $f_{\beta}(75-80 \%)$ is the averaged value between $75 \%$ and $80 \%$ RH. Additionally, $f_{\beta}(80 \%)$ was calculated by extrapolating the fit. Both values of the backscatter enhancement factor with respect to the reference $\mathrm{RH}$ of $40 \%$ can be found in Table 2. By taking a dry value at $40 \% \mathrm{RH}$, we underestimate the scattering enhancement factor by approximately $25 \%$ (Titos et al., 2016). The extrapolated values are a lot higher than the measured values at $75-80 \% \mathrm{RH}$. In the following discussion we will only use the measured enhancement factors. The error of the backscatter enhancement factor results from the standard deviation of the mean values at 40 and $75-80 \% \mathrm{RH}$ and the uncertainty introduced by the error in RH.

For a better comparison to reported literature values, we convert our backscatter enhancement factors $f_{\beta}$ to extinction enhancement factors $f_{\alpha}$ by means of the backscatter-toextinction ratio (lidar ratio $S$ ), which was measured for wet 

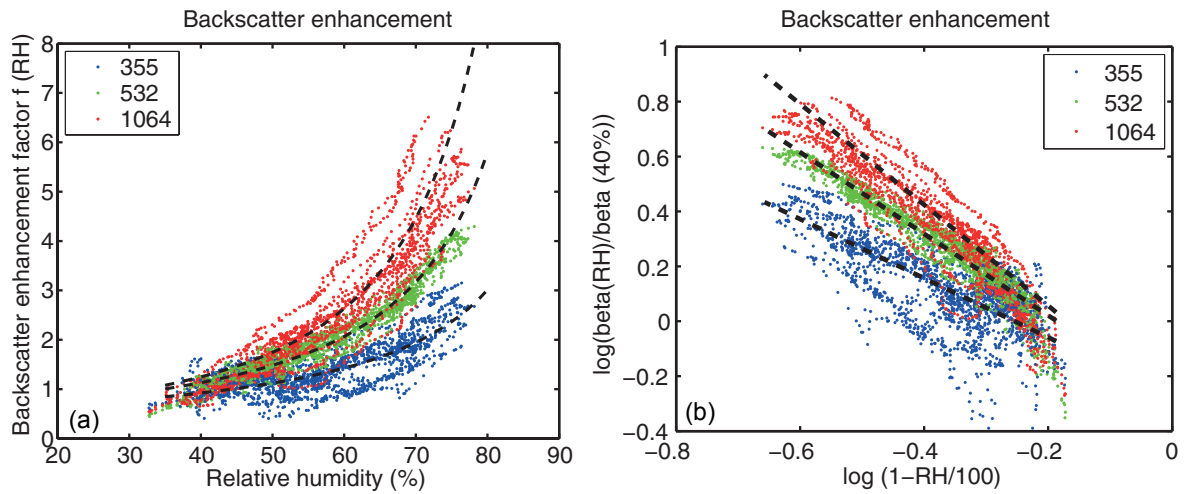

Figure 14. Backscatter enhancement factor for a dry value at $40 \% \mathrm{RH}$ (a) on a linear scale and (b) on a log-log scale. The three wavelengths are fitted separately by Eq. (2).

Table 2. The fit parameters for the backscatter enhancement factor according to Eq. (2). The backscatter enhancement factor $f_{\beta}(80 \%)$ calculated with these fit parameters is compared to the measured factor $f_{\beta}(75-80 \%)$ between 75 and $80 \%$ RH. The extinction enhancement factor $f_{\alpha}(75-80 \% \mathrm{RH})$ was derived by Eq. (3) to compare with the literature.

\begin{tabular}{lrrr|r|r}
\hline & \multicolumn{3}{c|}{ Fit } & \multicolumn{2}{c}{ Measurement } \\
\cline { 2 - 6 } Wavelength & $A$ & $\gamma$ & $f_{\beta}(80 \%)$ & $f_{\beta}(75-80 \%)$ & $f_{\alpha}(75-80 \%)$ \\
\hline $355 \mathrm{~nm}$ & 0.532 & 1.077 & 3.01 & $2.75 \pm 0.94$ & $1.94 \pm 0.94$ \\
$532 \mathrm{~nm}$ & 0.529 & 1.487 & 5.79 & $4.03 \pm 1.09$ & $3.70 \pm 1.14$ \\
$1064 \mathrm{~nm}$ & 0.489 & 1.837 & 9.40 & $5.52 \pm 1.47$ & $5.37 \pm 1.66^{*}$ \\
\hline
\end{tabular}

* Modeled lidar ratios used $\left(S_{\mathrm{wet}}=35 \mathrm{sr} ; S_{\mathrm{dry}}=36 \mathrm{sr}\right.$; Table 1$)$.

and dry marine particles (see Table 1 and and Fig. 11).

$f_{\alpha}(\mathrm{RH}, \lambda)=\frac{S_{\mathrm{wet}}}{S_{\mathrm{dry}}} f_{\beta}(\mathrm{RH}, \lambda)$

The extinction enhancement factor is commonly used in studies of the dependence of particle optical properties on RH (Kotchenruther et al., 1999; Zieger et al., 2010; Skupin et al., 2016). For $1064 \mathrm{~nm}$ the simulated lidar ratios (Table 1) have to be used. The errors of the lidar ratios are included in the error of $f_{\alpha}$ by Gaussian error propagation. Overall, the relative error of extinction enhancement factor is approximately $50 \%$ in the UV and $30 \%$ for the other wavelengths.

The measured extinction enhancement factors of pure marine aerosol range from $1.94 \pm 0.94$ (at $355 \mathrm{~nm}$ ) to $3.70 \pm 1.14$ (at $532 \mathrm{~nm}$ ) and $5.37 \pm 1.66$ (at $1064 \mathrm{~nm}$ ). A clear wavelength dependence is given. Qualitatively the same wavelength dependence of $f_{\alpha}$ was observed by Kotchenruther et al. (1999) for the wavelengths 450, 550, and $700 \mathrm{~nm}$.

By assuming a high single scattering albedo (ratio of scatter to extinction coefficient) for marine particle (Anderson et al., 1999; Takemura et al., 2002), the scattering and extinction enhancement factors should be almost equal.

The scattering enhancement factors in the present study are in the upper range of reported literature values for marine aerosol. This probably reflects the almost ideal marine conditions over Barbados during the winter season, when dust and pollution aerosol from Africa are at the lowest level and $5000 \mathrm{~km}$ upwind is only ocean. Zieger et al. $(2013)$ reported mean scattering enhancement factors $f(85 \%, 550 \mathrm{~nm})$ for sea salt of 2.28 at Mace Head, Ireland, 2.86 at Ny-Ålesund, Svalbard, and 3.38 at Cabauw, Netherlands. A review of mostly nephelometer-derived scattering enhancement factors at $550 \mathrm{~nm}$ is given in Titos et al. (2016), where the values for marine environments range between 1.5 and 3.5, depending on the amount of pollution. The hygroscopic growth of pure marine particles is strong compared to continental aerosol. The 7-year measurements in the Southern Great Plains, continental USA ( $900 \mathrm{~km}$ away from the ocean), yield a scattering enhancement factor $f(85 \%, 550 \mathrm{~nm})$ of $1.78 \mathrm{com}-$ pared to a dry value of $40 \%$ RH (Jefferson et al., 2017). Skupin et al. (2016) found in a 4-year measurement period over Leipzig, central Germany ( $400 \mathrm{~km}$ away from the ocean), an extinction enhancement factor $f(80 \%, 550 \mathrm{~nm})$ of $1.75 \pm 0.4$ compared to a dry value of $40 \%$ RH. For northwesterly wind directions (from the North Sea) the enhancement factor was slightly higher at Leipzig $(1.95 \pm 0.5)$.

\section{Comparison with optical modeling of sea salt cubes}

The optical properties of cubic sodium chloride particles were modeled by using the DDA. The model settings are de- 

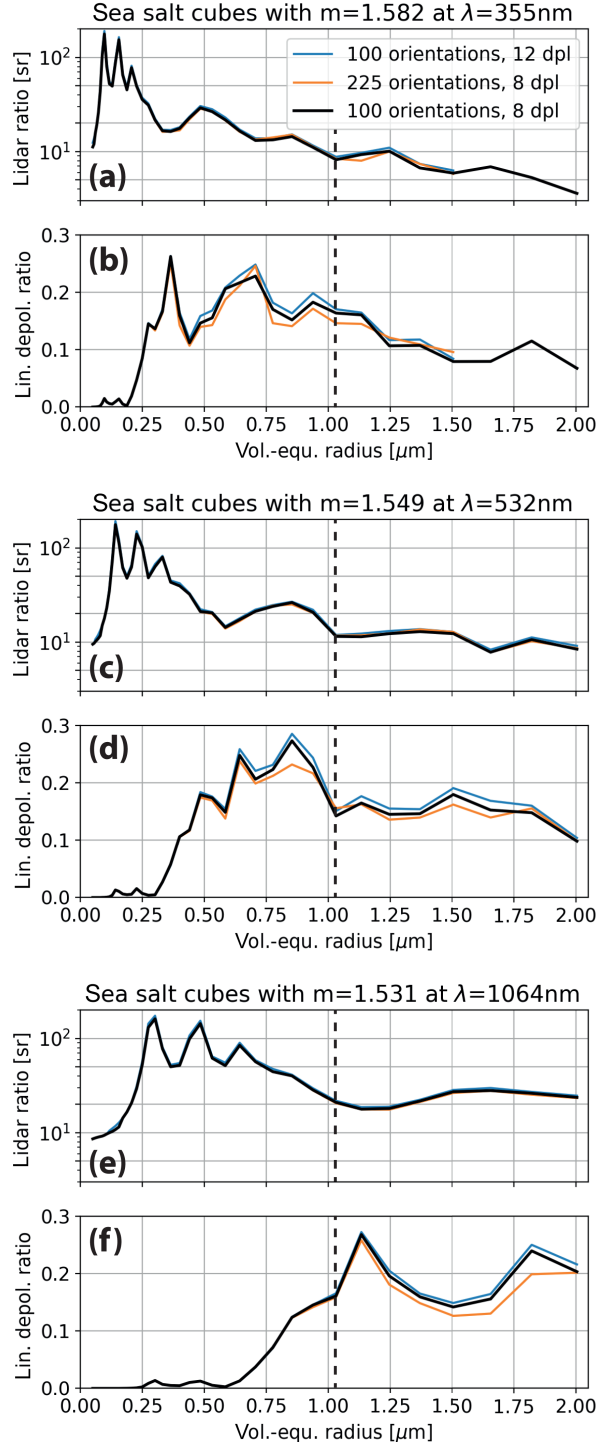

Figure 15. Simulation of the lidar ratio and the particle linear depolarization ratio for sea salt cubes depending on volume equivalent radius. The three lidar wavelengths are treated separately. The model simulations with increased number of dipoles (blue line) and orientations (orange line) are given as an estimation of the uncertainty. A dashed line marks the effective radius $\left(r_{\text {eff }}=1.033 \mu \mathrm{m}\right)$ of the AERONET size distribution given in Fig. 16. For the simulations of the cubic sea salt particles, the radius of the particles was reduced by a factor of 2 . Details are given in the text.

scribed in Sect. 3.3. The lidar ratio and PLDR for each wavelength were modeled as a function of particle size (Fig. 15). If the particle diameter is close to the laser wavelength $(\lambda)$ and smaller, the lidar ratio is high (up to more than $100 \mathrm{sr}$ ). For particle diameters $>2 \lambda$, the lidar ratio is $20 \pm 10 \mathrm{sr}$. The lidar ratio decreases with further increasing particle size, e.g., down to $3.6 \mathrm{sr}$ for the radius $r=2 \mu \mathrm{m}$ at $355 \mathrm{~nm}$. If the particle diameter is smaller than the wavelength, the PLDR is very small. A significant depolarization is produced for particle

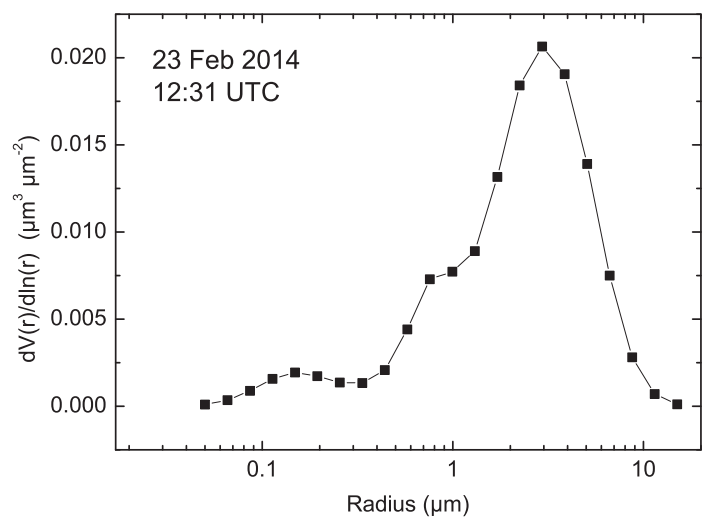

Figure 16. AERONET particle volume size distribution for 23 February 2014, 12:31 UTC, at Ragged Point, version 1.5 (Holben et al., 1998; AERONET, 2017).

diameters $\geq \lambda$. Then, values up to 0.27 are reached, although they vary strongly with particle size. In the atmosphere, we have always a distribution of particles sizes and so extreme optical effects are widely smoothed out.

We consider the size distribution inverted by the AERONET algorithm (Holben et al., 1998) from measurements at Ragged Point on 23 February 2014 at 12:31 UTC (Fig. 16). It is version 1.5 only, but the inversion of that measurement resulted in the lowest residual error of the sky radiance on that day. We assume that the optical depth during that measurement was dominated by wet marine particles. To calculate the optical properties for dry marine particles we assume that their size is a factor of 2 smaller compared to the size obtained by AERONET and assume that the lidar ratio and the linear depolarization ratio for particles with $r>2 \mu \mathrm{m}$ is the same as for $r=2 \mu \mathrm{m}$ particles. The results are given in Table 1 . In the UV the simulated PLDR for the reduced radius agrees with the measurements. At $532 \mathrm{~nm}$ the model underestimates the PLDR, but it is still within the uncertainties of the lidar system. Whereas at $1064 \mathrm{~nm}$, the model overestimate the PLDR. By using the dry radius size distribution (a factor of 2 lower radii) the agreement of the spectral slope of PLDR is much better than using the original AERONET distribution.

The T-matrix results for cubic sea salt (David et al., 2013) are given for comparison (Table 1). They agree with the maximum PLDR in the UV and visible (see Fig. 12d and e), whereas the 30 min mean PLDRs (Table 1) are smaller. The simulations of cubic particles by Kemppinen et al. (2015a) are limited by the maximum size parameter $(x=10)$. Taking the effective radius $(1.033 \mu \mathrm{m})$ from the AERONET size distribution (Fig. 16) into account, the lidar ratio (18 $\pm 2 \mathrm{sr}$ ) and the PLDR $(0.15 \pm 0.05)$ can be determined at $1064 \mathrm{~nm}$ only.

Chamaillard et al. (2003) showed in a modeling study that a cubic shape assumption (DDA model) is necessary to reproduce the backscatter of dry marine particles. Their mod- 
eled scattering coefficient could not reproduce the measurements no matter which shape is assumed.

The modeled lidar ratios are smaller than the measured ones. It is evident that the low modeled lidar ratios at $355 \mathrm{~nm}$ (Table 1) are due to the very low lidar ratios of particles $r>1 \mu \mathrm{m}$ (see Fig. 15a). Thus, the deviation between measurements and the models is an indication that our applied size distributions contain too many large particles. The uncertainty in the lidar ratio for dried marine particles in the UV is high. Nevertheless, there is no large difference between wet and dry marine lidar ratios.

\section{Conclusions}

The phase transition between spherical sea salt droplets and cubic-like sea salt crystals has been observed under pure marine conditions over Barbados. The particle linear depolarization ratio, measured with a triple-wavelength polarization lidar, significantly increased when RH dropped below $50 \%$. The combination of polarization and water vapor measurements with lidar offered the unique opportunity to study this behavior with high vertical and temporal resolution. The particle linear depolarization ratio in these dried marine layers was enhanced on 23 and 24 February 2014 (0.05-0.12 at $355 \mathrm{~nm}, 0.07-0.15$ at $532 \mathrm{~nm}$, and $0.04-0.10$ at $1064 \mathrm{~nm}$ ). The systematic investigations of the depolarization ratio for dry marine particles showed maximum values (with systematic uncertainty) of $0.12 \pm 0.08$ (at $355 \mathrm{~nm}$ ), $0.15 \pm 0.03$ (at $532 \mathrm{~nm}$ ), and $0.10 \pm 0.01$ at $1064 \mathrm{~nm}$.

We compared the optical properties for dry and wet marine particles at three wavelengths at 40 and $80 \% \mathrm{RH}$, respectively. Complete dry $(0 \% \mathrm{RH})$ sea salt particles could not be found under atmospheric conditions. The extinction enhancement factor for the range 40 to $80 \% \mathrm{RH}$ is $1.94 \pm 0.94$ (at $355 \mathrm{~nm}$ ), $3.70 \pm 1.14$ (at $532 \mathrm{~nm}$ ), and $5.37 \pm 1.66$ (at $1064 \mathrm{~nm}$ ). These results are given in Tables 1 and 2.

A layer of dried marine aerosol observed over Barbados in February 2014 probably often exists at the MAL top when dry free-tropospheric air mixes with humid air in the uppermost part of the MAL. Extended layers with dried marine particles, as observed on 23 February, may also occur frequently when the residual layer in the MAL is isolated from the convectively active MBL, and this residual layer entrains dry air from the free troposphere.

Satellite-based studies, for example with CALIPSO or EarthCARE, would be helpful to assess the global occurrence of dried MALs. These changes in particle shape may have an impact on the Earth's radiative budget over the oceans and therefore should be studied with global atmospheric models, although the impact of thin layers of dry marine particles may be low compared to the thicker layers of humid marine particles below.

Assuming generally spheroidal shape for nonspherical particles causes errors in the case of marine observations. In- version algorithms as used in AERONET (Dubovik et al., 2006) may be affected as well. For dry marine cases, we suggest that a cubic model could be included.

An enhanced depolarization ratio for dry sea salt particles (up to 0.15 at $532 \mathrm{~nm}$ ) leads to an overestimation of dust in aerosol classification and separation schemes (Burton et al., 2012; Groß et al., 2013; Mamouri and Ansmann, 2014, 2017), so one should be careful in marine environments (decrease in RH in upper part of MAL) and at coasts (sea breeze effects and decrease in RH over land). Marine particles can be injected into the SAL by convective cumulus convection, where RH is typically below $40 \%$ and thus marine particles have a cubic-like shape. Mistyping of aerosol layers will lead to wrong results in further retrieved products, such as the extinction coefficient, the mass concentration, or the estimates of cloud condensation nuclei and ice nucleating particles (Mamouri and Ansmann, 2016).

The existence of cubic-like and spherical salt particles has been known for a long time, but this study points out the atmospheric relevance. Cubic-like sea salt has been measured under atmospheric conditions. The two shape modes of sea salt (spherical and cubic-like) exist under atmospheric conditions over the ocean and should be considered in future aerosol studies.

Data availability. The data sets are available at the Leibniz Institute for Tropospheric Research and can be obtained upon request.

Competing interests. The authors declare that they have no conflict of interest.

Special issue statement. This article is part of the special issue "The Saharan Aerosol Long-range Transport and Aerosol-Cloud interaction Experiment (SALTRACE) (ACP/AMT inter-journal SI)". It does not belong to a conference.

Acknowledgements. Konrad Kandler acknowledges support from the Deutsche Forschungsgemeinschaft (grant KA 2280/2). Josef Gasteiger has received funding from the European Research Council (ERC) under the European Union's Horizon 2020 research and innovation programme (grant agreement no. 640458, A-LIFE). The logistical support of the Caribbean Institute for Meteorology and Hydrology (CIMH), Husbands, Barbados, should be acknowledged. The authors want to express their gratitude to the three anonymous referees and Paul Zieger for carefully reading the manuscript and providing helpful comments to improve it.

Edited by: Joshua Schwarz

Reviewed by: three anonymous referees 


\section{References}

Adachi, K. and Buseck, P. R.: Changes in shape and composition of sea-salt particles upon aging in an urban atmosphere, Atmos. Environ., 100, 1-9, https://doi.org/10.1016/j.atmosenv.2014.10.036, 2015.

AERONET: Aerosol Robotic Network aerosol data base, available at: https://aeronet.gsfc.nasa.gov/, last access: 22 March 2017.

Anderson, T. L., Covert, D. S., Wheeler, J. D., Harris, J. M., Perry, K. D., Trost, B. E., Jaffe, D. J., and Ogren, J. A.: Aerosol backscatter fraction and single scattering albedo: Measured values and uncertainties at a coastal station in the Pacific Northwest, J. Geophys. Res.-Atmos., 104, 26793-26807, https://doi.org/10.1029/1999JD900172,1999.

Ansmann, A., Wandinger, U., Riebesell, M., Weitkamp, C., and Michaelis, W.: Independent measurement of extinction and backscatter profiles in cirrus clouds by using a combined Raman elastic-backscatter lidar, Appl. Opt., 31, 7113-7131, https://doi.org/10.1364/AO.31.007113, 1992.

Ansmann, A., Petzold, A., Kandler, K., Tegen, I., Wendisch, M., Müller, D., Weinzierl, B., Müller, T., and Heintzenberg, J.: Saharan Mineral Dust Experiments SAMUM-1 and SAMUM-2: what have we learned?, Tellus B, 63, 403-429, https://doi.org/10.1111/j.1600-0889.2011.00555.x, 2011.

Ansmann, A., Rittmeister, F., Engelmann, R., Basart, S., Benedetti, A., Spyrou, C., Skupin, A., Baars, H., Seifert, P., Senf, F., and Kanitz, T.: Profiling of Saharan dust from the Caribbean to West Africa, Part 2: Shipborne lidar measurements versus forecasts, Atmos. Chem. Phys. Discuss., https://doi.org/10.5194/acp-2017502, in review, 2017.

Baars, H., Ansmann, A., Althausen, D., Engelmann, R., Artaxo, P., Pauliquevis, T., and Souza, R.: Further evidence for significant smoke transport from Africa to Amazonia, Geophys. Res. Lett., 38, L20802, https://doi.org/10.1029/2011GL049200, 2011.

Bates, T. S., Kapustin, V. N., Quinn, P. K., Covert, D. S., Coffman, D. J., Mari, C., Durkee, P. A., De Bruyn, W. J., and Saltzman, E. S.: Processes controlling the distribution of aerosol particles in the lower marine boundary layer during the First Aerosol Characterization Experiment (ACE 1), J. Geophys. Res.-Atmos., 103, 16369-16383, https://doi.org/10.1029/97JD03720, 1998.

Burton, S. P., Ferrare, R. A., Hostetler, C. A., Hair, J. W., Rogers, R. R., Obland, M. D., Butler, C. F., Cook, A. L., Harper, D. B., and Froyd, K. D.: Aerosol classification using airborne High Spectral Resolution Lidar measurements - methodology and examples, Atmos. Meas. Tech., 5, 73-98, https://doi.org/10.5194/amt-5-732012, 2012.

Carrico, C. M., Kus, P., Rood, M. J., Quinn, P. K., and Bates, T. S.: Mixtures of pollution, dust, sea salt, and volcanic aerosol during ACE-Asia: Radiative properties as a function of relative humidity, J. Geophys. Res.-Atmos., 108, 8650, https://doi.org/10.1029/2003JD003405, 2003.

Chamaillard, K., Jennings, S., Kleefeld, C., Ceburnis, D., and Yoon, Y.: Light backscattering and scattering by nonspherical sea-salt aerosols, J. Quant. Spectrosc. Ra., 79-80, 577-597, https://doi.org/10.1016/S0022-4073(02)00309-6, 2003.

Dadashazar, H., Wang, Z., Crosbie, E., Brunke, M., Zeng, X., Jonsson, H., Woods, R. K., Flagan, R. C., Seinfeld, J. H., and Sorooshian, A.: Relationships between giant sea salt particles and clouds inferred from aircraft physico- chemical data, J. Geophys. Res.-Atmos., 122, 3421-3434, https://doi.org/10.1002/2016JD026019, 2017.

David, G., Thomas, B., Nousiainen, T., Miffre, A., and Rairoux, P.: Retrieving simulated volcanic, desert dust and sea-salt particle properties from two/three-component particle mixtures using UV-VIS polarization lidar and $\mathrm{T}$ matrix, Atmos. Chem. Phys., 13, 6757-6776, https://doi.org/10.5194/acp-136757-2013, 2013.

DeMott, P. J., Hill, T. C. J., McCluskey, C. S., Prather, K. A., Collins, D. B., Sullivan, R. C., Ruppel, M. J., Mason, R. H., Irish, V. E., Lee, T., Hwang, C. Y., Rhee, T. S., Snider, J. R., McMeeking, G. R., Dhaniyala, S., Lewis, E. R., Wentzell, J. J. B., Abbatt, J., Lee, C., Sultana, C. M., Ault, A. P., Axson, J. L., Diaz Martinez, M., Venero, I., Santos-Figueroa, G., Stokes, M. D., Deane, G. B., Mayol-Bracero, O. L., Grassian, V. H., Bertram, T. H., Bertram, A. K., Moffett, B. F., and Franc, G. D.: Sea spray aerosol as a unique source of ice nucleating particles, P. Natl. Acad. Sci. USA, 113, 5797-5803, https://doi.org/10.1073/pnas.1514034112, 2016.

Dubovik, O., Sinyuk, A., Lapyonok, T., Holben, B. N., Mishchenko, M., Yang, P., Eck, T. F., Volten, H., Muñoz, O., Veihelmann, B., van der Zande, W. J., Leon, J.-F., Sorokin, M., and Slutsker, I.: Application of spheroid models to account for aerosol particle nonsphericity in remote sensing of desert dust, J. Geophys. Res.Atmos., 111, D11208, https://doi.org/10.1029/2005JD006619, 2006.

Eldridge, J. and Palik, E.: Handbook of Optical Constants of Solids, chap. Sodium Chloride, Academic Press, Inc., Orlando, FL, 775793, 1985.

Facchini, M. C., Rinaldi, M., Decesari, S., Carbone, C., Finessi, E., Mircea, M., Fuzzi, S., Ceburnis, D., Flanagan, R., Nilsson, E. D., de Leeuw, G., Martino, M., Woeltjen, J., and O'Dowd, C. D.: Primary submicron marine aerosol dominated by insoluble organic colloids and aggregates, Geophys. Res. Lett., 35, L17814, https://doi.org/10.1029/2008GL034210, 2008.

Freudenthaler, V.: About the effects of polarising optics on lidar signals and the $\Delta 90$ calibration, Atmos. Meas. Tech., 9, 41814255, https://doi.org/10.5194/amt-9-4181-2016, 2016.

Freudenthaler, V., Esselborn, M., Wiegner, M., Heese, B., Tesche, M., Ansmann, A., Müller, D., Althausen, D., Wirth, M., Fix, A., Ehret, G., Knippertz, P., Toledano, C., Gasteiger, J., Garhammer, M., and Seefeldner, M.: Depolarization ratio profiling at several wavelengths in pure Saharan dust during SAMUM 2006, Tellus B, 61, 165-179, https://doi.org/10.1111/j.16000889.2008.00396.x, 2009.

Friedl, M., McIver, D., Hodges, J., Zhang, X., Muchoney, D., Strahler, A., Woodcock, C., Gopal, S., Schneider, A., Cooper, A., Baccini, A., Gao, F., and Schaaf, C.: Global land cover mapping from MODIS: algorithms and early results, Remote Sens. Environ., 83, 287-302, https://doi.org/10.1016/S00344257(02)00078-0, 2002.

Gantt, B. and Meskhidze, N.: The physical and chemical characteristics of marine primary organic aerosol: a review, Atmos. Chem. Phys., 13, 3979-3996, https://doi.org/10.5194/acp13-3979-2013, 2013.

Gasteiger, J., Wiegner, M., Groß, S., Freudenthaler, V., Toledano, C., Tesche, M., and Kandler, K.: Modelling lidar-relevant optical properties of complex mineral dust aerosols, Tellus B, 63, 725741, https://doi.org/10.1111/j.1600-0889.2011.00559.x, 2011. 
Granados-Muñoz, M. J., Navas-Guzmán, F., Bravo-Aranda, J. A., Guerrero-Rascado, J. L., Lyamani, H., Valenzuela, A., Titos, G., Fernández-Gálvez, J., and Alados-Arboledas, L.: Hygroscopic growth of atmospheric aerosol particles based on active remote sensing and radiosounding measurements: selected cases in southeastern Spain, Atmos. Meas. Tech., 8, 705-718, https://doi.org/10.5194/amt-8-705-2015, 2015.

Groß, S., Esselborn, M., Weinzierl, B., Wirth, M., Fix, A., and Petzold, A.: Aerosol classification by airborne high spectral resolution lidar observations, Atmos. Chem. Phys., 13, 2487-2505, https://doi.org/10.5194/acp-13-2487-2013, 2013.

Haarig, M., Althausen, D., Ansmann, A., Klepel, A., Baars, H., Engelmann, R., Groß, S., and Freudenthaler, V.: Measurement of the Linear Depolarization Ratio of Aged Dust at Three Wavelengths (355, 532 and $1064 \mathrm{~nm}$ ) Simultaneously over Barbados, EPJ Web of Conferences, 119, 18009, https://doi.org/10.1051/epjconf/201611918009, 2016a.

Haarig, M., Engelmann, R., Ansmann, A., Veselovskii, I., Whiteman, D. N., and Althausen, D.: $1064 \mathrm{~nm}$ rotational Raman lidar for particle extinction and lidar-ratio profiling: cirrus case study, Atmos. Meas. Tech., 9, 4269-4278, https://doi.org/10.5194/amt9-4269-2016, 2016b

Haarig, M., Ansmann, A., Althausen, D., Klepel, A., Groß, S., Freudenthaler, V., Toledano, C., Mamouri, R.-E., Farrell, D. A., Prescod, D. A., Marinou, E., Burton, S. P., Gasteiger, J., Engelmann, R., and Baars, H.: Triple-wavelength depolarizationratio profiling of Saharan dust over Barbados during SALTRACE in 2013 and 2014, Atmos. Chem. Phys., 17, 10767-10794, https://doi.org/10.5194/acp-17-10767-2017, 2017.

Hänel, G.: The Properties of Atmospheric Aerosol Particles as Functions of the Relative Humidity at Thermodynamic Equilibrium with the Surrounding Moist Air, Adv. Geophys., 19, 73 188, https://doi.org/10.1016/S0065-2687(08)60142-9, 1976.

Heintzenberg, J.: The SAMUM-1 experiment over Southern Morocco: overview and introduction, Tellus B, 61, 2-11, https://doi.org/10.1111/j.1600-0889.2008.00403.x, 2009.

Holben, B., Eck, T., Slutsker, I., Tanré, D., Buis, J., Setzer, A., Vermote, E., Reagan, J., Kaufman, Y., Nakajima, T., Lavenu, F., Jankowiak, I., and Smirnov, A.: AERONET-A Federated Instrument Network and Data Archive for Aerosol Characterization, Remote Sens. Environ., 66, 1-16, https://doi.org/10.1016/S00344257(98)00031-5, 1998.

HYSPLIT: HYbrid Single-Particle Lagrangian Integrated Trajectory model, backward trajectory calculation tool, available at: http://ready.arl.noaa.gov/HYSPLIT.php, last access: 14 September 2017.

Järvinen, E., Kemppinen, O., Nousiainen, T., Kociok, T., Möhler, O., Leisner, T., and Schnaiter, M.: Laboratory investigations of mineral dust near-backscattering depolarization ratios, J. Quant. Spectrosc. Ra., 178, 192-208, https://doi.org/10.1016/j.jqsrt.2016.02.003, 2016.

Jefferson, A., Hageman, D., Morrow, H., Mei, F., and Watson, T.: Seven years of aerosol scattering hygroscopic growth measurements from SGP: Factors influencing water uptake, J. Geophys. Res.-Atmos., 122, 2017JD026804, https://doi.org/10.1002/2017JD026804, 2017.

Kandler, K., Benker, N., Bundke, U., Cuevas, E., Ebert, M., Knippertz, P., Rodríuez, S., Schütz, L., and Weinbruch, S.: Chemical composition and complex refractive index of
Saharan Mineral Dust at Izaña, Tenerife (Spain) derived by electron microscopy, Atmos. Environ., 41, 8058-8074, https://doi.org/10.1016/j.atmosenv.2007.06.047, 2007.

Kandler, K., Lieke, K., Benker, N., Emmel, C., Küpper, M., MüllerEbert, D., Ebert, M., Scheuvens, D., Schladitz, A., Schütz, L., and Weinbruch, S.: Electron microscopy of particles collected at Praia, Cape Verde, during the Saharan Mineral Dust Experiment: particle chemistry, shape, mixing state and complex refractive index, Tellus B, 63, 475-496, https://doi.org/10.1111/j.16000889.2011.00550.x, 2011.

Kanitz, T., Ansmann, A., Engelmann, R., and Althausen, D.: Northsouth cross sections of the vertical aerosol distribution over the Atlantic Ocean from multiwavelength Raman/polarization lidar during Polarstern cruises, J. Geophys. Res.-Atmos., 118, $2643-$ 2655, https://doi.org/10.1002/jgrd.50273, 2013.

Karyampudi, V. M., Palm, S. P., Reagen, J. A., Fang, H., Grant, W. B., Hoff, R. M., Moulin, C., Pierce, H. F., Torres, O., Browell, E. V., and Melfi, S. H.: Validation of the Saharan Dust Plume Conceptual Model Using Lidar, Meteosat, and ECMWF Data, B. Am. Meteorol. Soc., 80, 1045-1075, https://doi.org/10.1175/15200477(1999)080<1045:VOTSDP>2.0.CO;2, 1999.

Kasten, F.: Visibility forecast in the phase of pre-condensation, Tellus, 21, 631-635, https://doi.org/10.3402/tellusa.v21i5.10112, 1969.

Kemppinen, O., Nousiainen, T., and Lindqvist, H.: The impact of surface roughness on scattering by realistically shaped wavelength-scale dust particles, J. Quant. Spectrosc. Ra., 150, 55-67, https://doi.org/10.1016/j.jqsrt.2014.05.024, 2015a.

Kemppinen, O., Nousiainen, T., Merikallio, S., and Räisänen, P.: Retrieving microphysical properties of dust-like particles using ellipsoids: the case of refractive index, Atmos. Chem. Phys., 15, 11117-11132, https://doi.org/10.5194/acp-15-11117-2015, 2015b.

Kotchenruther, R. A., Hobbs, P. V., and Hegg, D. A.: Humidification factors for atmospheric aerosols off the mid-Atlantic coast of the United States, J. Geophys. Res.-Atmos., 104, 2239-2251, https://doi.org/10.1029/98JD01751, 1999.

Kristensen, T. B., Müller, T., Kandler, K., Benker, N., Hartmann, M., Prospero, J. M., Wiedensohler, A., and Stratmann, F.: Properties of cloud condensation nuclei $(\mathrm{CCN})$ in the trade wind marine boundary layer of the western North Atlantic, Atmos. Chem. Phys., 16, 2675-2688, https://doi.org/10.5194/acp-162675-2016, 2016.

Laskin, A., Moffet, R. C., Gilles, M. K., Fast, J. D., Zaveri, R. A., Wang, B., Nigge, P., and Shutthanandan, J.: Tropospheric chemistry of internally mixed sea salt and organic particles: Surprising reactivity of $\mathrm{NaCl}$ with weak organic acids, J. Geophys. Res.Atmos., 117, D15302, https://doi.org/10.1029/2012JD017743, 2012.

Mamouri, R. E. and Ansmann, A.: Fine and coarse dust separation with polarization lidar, Atmos. Meas. Tech., 7, 3717-3735, https://doi.org/10.5194/amt-7-3717-2014, 2014.

Mamouri, R.-E. and Ansmann, A.: Potential of polarization lidar to provide profiles of $\mathrm{CCN}$ - and INP-relevant aerosol parameters, Atmos. Chem. Phys., 16, 5905-5931, https://doi.org/10.5194/acp-16-5905-2016, 2016.

Mamouri, R.-E. and Ansmann, A.: Potential of polarization/Raman lidar to separate fine dust, coarse dust, maritime, and anthro- 
pogenic aerosol profiles, Atmos. Meas. Tech., 10, 3403-3427, https://doi.org/10.5194/amt-10-3403-2017, 2017.

Mattis, I., Ansmann, A., Althausen, D., Jaenisch, V., Wandinger, U., Müller, D., Arshinov, Y. F., Bobrovnikov, S. M., and Serikov, I. B.: Relative-humidity profiling in the troposphere with a Raman lidar, Appl. Opt., 41, 6451-6462, https://doi.org/10.1364/AO.41.006451, 2002.

Middlebrook, A. M., Murphy, D. M., and Thomson, D. S.: Observations of organic material in individual marine particles at Cape Grim during the First Aerosol Characterization Experiment (ACE 1), J. Geophys. Res.-Atmos., 103, 16475-16483, https://doi.org/10.1029/97JD03719, 1998.

Müller, D., Ansmann, A., Mattis, I., Tesche, M., Wandinger, U., Althausen, D., and Pisani, G.: Aerosol-type-dependent lidar ratios observed with Raman lidar, J. Geophys. Res.-Atmos., 112, D16202, https://doi.org/10.1029/2006JD008292, 2007.

Müller, D., Veselovskii, I., Kolgotin, A., Tesche, M., Ansmann, A., and Dubovik, O.: Vertical profiles of pure dust and mixed smoke-dust plumes inferred from inversion of multiwavelength Raman/polarization lidar data and comparison to AERONET retrievals and in situ observations, Appl. Opt., 52, 3178-3202, https://doi.org/10.1364/AO.52.003178, 2013.

Murayama, T., Okamoto, H., Kaneyasu, N., Kamataki, H., and Miura, K.: Application of lidar depolarization measurement in the atmospheric boundary layer: Effects of dust and seasalt particles, J. Geophys. Res.-Atmos., 104, 31781-31792, https://doi.org/10.1029/1999JD900503, 1999.

O’Dowd, C. D., Smith, M. H., Consterdine, I. E., and Lowe, J. A.: Marine aerosol, sea-salt, and the marine sulphur cycle: a short review, Atmos. Environ., 31, 73-80, https://doi.org/10.1016/S1352-2310(96)00106-9, 1997.

Omar, A. H., Winker, D. M., Vaughan, M. A., Hu, Y., Trepte, C. R., Ferrare, R. A., Lee, K.-P., Hostetler, C. A., Kittaka, C., Rogers, R. R., Kuehn, R. E., and Liu, Z.: The CALIPSO Automated Aerosol Classification and Lidar Ratio Selection Algorithm, J. Atmos. Ocean. Tech., 26, 1994-2014, https://doi.org/10.1175/2009JTECHA1231.1, 2009.

Piller, N. B. and Martin, O. J. F.: Increasing the performance of the coupled-dipole approximation: a spectral approach, IEEE T. Antenn. Propag., 46, 1126-1137, https://doi.org/10.1109/8.718567, 1998.

Rittmeister, F., Ansmann, A., Engelmann, R., Skupin, A., Baars, H., Kanitz, T., and Kinne, S.: Profiling of Saharan dust from the Caribbean to western Africa - Part 1: Layering structures and optical properties from shipborne polarization/Raman lidar observations, Atmos. Chem. Phys., 17, 12963-12983, https://doi.org/10.5194/acp-17-12963-2017, 2017.

Sakai, T., Shibata, T., Kwon, S.-A., Kim, Y.-S., Tamura, K., and Iwasaka, Y.: Free tropospheric aerosol backscatter, depolarization ratio, and relative humidity measured with the Raman lidar at Nagoya in 1994-1997: contributions of aerosols from the Asian Continent and the Pacific Ocean, Atmos. Environ., 34, 431-442, https://doi.org/10.1016/S1352-2310(99)00328-3, 2000 .

Sakai, T., Nagai, T., Zaizen, Y., and Mano, Y.: Backscattering linear depolarization ratio measurements of mineral, sea-salt, and ammonium sulfate particles simulated in a laboratory chamber, Appl. Opt., 49, 4441-4449, https://doi.org/10.1364/AO.49.004441, 2010.
Sayer, A. M., Smirnov, A., Hsu, N. C., and Holben, B. N.: A pure marine aerosol model, for use in remote sensing applications, J. Geophys. Res.-Atmos., 117, D05213, https://doi.org/10.1029/2011JD016689, 2012.

Skupin, A., Ansmann, A., Engelmann, R., Seifert, P., and Müller, T.: Four-year long-path monitoring of ambient aerosol extinction at a central European urban site: dependence on relative humidity, Atmos. Chem. Phys., 16, 1863-1876, https://doi.org/10.5194/acp-16-1863-2016, 2016.

Sloan, I. H. and Womersley, R. S.: Extremal Systems of Points and Numerical Integration on the Sphere, Adv. Comput. Math., 21, 107-125, https://doi.org/10.1023/B:ACOM.0000016428.25905.da, 2004.

Smirnov, A., Holben, B. N., Kaufman, Y. J., Dubovik, O., Eck, T. F., Slutsker, I., Pietras, C., and Halthore, R. N.: Optical Properties of Atmospheric Aerosol in Maritime Environments, J. Atmos. Sci., 59, 501-523, https://doi.org/10.1175/15200469(2002)059<0501:OPOAAI>2.0.CO;2, 2002.

Stein, A. F., Draxler, R. R., Rolph, G. D., Stunder, B. J. B., Cohen, M. D., and Ngan, F.: NOAA's HYSPLIT Atmospheric Transport and Dispersion Modeling System, B. Am. Meteorol. Soc., 96, 2059-2077, https://doi.org/10.1175/BAMS-D-14$00110.1,2015$.

Sugimoto, N. and Lee, C. H.: Characteristics of dust aerosols inferred from lidar depolarization measurements at two wavelengths, Appl. Opt., 45, 7468-7474, https://doi.org/10.1364/AO.45.007468, 2006.

Sugimoto, N., Matsui, I., Liu, Z., Shimizu, A., Takamushi, I., and Asai, K.: Observation of Aerosols and Clouds Using a TwoWavelength Polarization Lidar during the Nauru99 Experiment, J. Mar. Meteorol. Soc. Jpn., 76, 93-98, 2000.

Takemura, T., Nakajima, T., Dubovik, O., Holben, B. N., and Kinne, S.: Single-Scattering Albedo and Radiative Forcing of Various Aerosol Species with a Global Three-Dimensional Model, J. Climate, 15, 333-352, https://doi.org/10.1175/15200442(2002)015<0333:SSAARF>2.0.CO;2, 2002.

Tang, I., Tridico, A., and Fung, K.: Thermodynamic and Optical Properties of sea salt aerosols, J. Geophys. Res.-Atmos., 102, 23269-23275, 1997.

Tervahattu, H., Juhanoja, J., and Kupiainen, K.: Identification of an organic coating on marine aerosol particles by TOFSIMS, J. Geophys. Res.-Atmos., 107, ACH 18-1-ACH 18-7, https://doi.org/10.1029/2001JD001403, 2002.

Tesche, M., Ansmann, A., Müller, D., Althausen, D., Engelmann, R., Freudenthaler, V., and Groß, S.: Vertically resolved separation of dust and smoke over Cape Verde using multiwavelength Raman and polarization lidars during Saharan Mineral Dust Experiment 2008, J. Geophys. Res.-Atmos., 114, D13202, https://doi.org/10.1029/2009JD011862, 2009.

Titos, G., Cazorla, A., Zieger, P., Andrews, E., Lyamani, H., Granados-Muñoz, M., Olmo, F., and Alados-Arboledas, L.: Effect of hygroscopic growth on the aerosol lightscattering coefficient: A review of measurements, techniques and error sources, Atmos. Environ., 141, 494-507, https://doi.org/10.1016/j.atmosenv.2016.07.021, 2016.

Veselovskii, I., Whiteman, D. N., Kolgotin, A., Andrews, E., and Korenskii, M.: Demonstration of Aerosol Property Profiling by Multiwavelength Lidar under Varying Relative Hu- 
midity Conditions, J. Atmos. Ocean. Tech., 26, 1543-1557, https://doi.org/10.1175/2009JTECHA1254.1, 2009.

Veselovskii, I., Dubovik, O., Kolgotin, A., Lapyonok, T., Di Girolamo, P., Summa, D., Whiteman, D. N., Mishchenko, M., and Tanré, D.: Application of randomly oriented spheroids for retrieval of dust particle parameters from multiwavelength lidar measurements, J. Geophys. Res.-Atmos., 115, D21203, https://doi.org/10.1029/2010JD014139, 2010.

Wandinger, U. and Ansmann, A.: Experimental Determination of the Lidar Overlap Profile with Raman Lidar, Appl. Opt., 41, 511514, https://doi.org/10.1364/AO.41.000511, 2002.

Wang, Z., King, S. M., Freney, E., Rosenoern, T., Smith, M. L., Chen, Q., Kuwata, M., Lewis, E. R., Pöschl, U., Wang, W., Buseck, P. R., and Martin, S. T.: The Dynamic Shape Factor of Sodium Chloride Nanoparticles as Regulated by Drying Rate, Aerosol Sci. Technol., 44, 939-953, https://doi.org/10.1080/02786826.2010.503204, 2010.

Weinzierl, B., Ansmann, A., Prospero, J. M., Althausen, D., Benker, N., Chouza, F., Dollner, M., Farrell, D., Fomba, W. K., Freudenthaler, V., Gasteiger, J., Groß, S., Haarig, M., Heinold, B., Kandler, K., Kristensen, T. B., Mayol-Bracero, O. L., Müller, T., Reitebuch, O., Sauer, D., Schäfler, A., Schepanski, K., Spanu, A., Tegen, I., Toledano, C., and Walser, A.: The Saharan Aerosol Long-range Transport and Aerosol-Cloud-Interaction Experiment (SALTRACE): overview and selected highlights, B. Am. Meteorol. Soc., 98, 1427-1451, https://doi.org/10.1175/BAMSD-15-00142.1, 2017.

Wex, H., Dieckmann, K., Roberts, G. C., Conrath, T., Izaguirre, M. A., Hartmann, S., Herenz, P., Schäfer, M., Ditas, F., Schmeissner, T., Henning, S., Wehner, B., Siebert, H., and Stratmann, F.: Aerosol arriving on the Caribbean island of Barbados: physical properties and origin, Atmos. Chem. Phys., 16, 14107-14130, https://doi.org/10.5194/acp-16-14107-2016, 2016.

Whiteman, D. N., Melfi, S. H., and Ferrare, R. A.: Raman lidar system for the measurement of water vapor and aerosols in the Earth's atmosphere, Appl. Opt., 31, 3068-3082, https://doi.org/10.1364/AO.31.003068, 1992.
Wise, M. E., Biskos, G., Martin, S. T., Russell, L. M., and Buseck, P. R.: Phase Transitions of Single Salt Particles Studied Using a Transmission Electron Microscope with an Environmental Cell, Aerosol Sci. Technol., 39, 849-856, https://doi.org/10.1080/02786820500295263, 2005.

Wise, M. E., Semeniuk, T. A., Bruintjes, R., Martin, S. T., Russell, L. M., and Buseck, P. R.: Hygroscopic behavior of NaClbearing natural aerosol particles using environmental transmission electron microscopy, J. Geophys. Res.-Atmos., 112, D10224, https://doi.org/10.1029/2006JD007678, 2007.

Yurkin, M. A. and Hoekstra, A. G.: The discrete-dipoleapproximation code ADDA: Capabilities and known limitations, J. Quant. Spectrosc. Ra., 112, 2234-2247, https://doi.org/10.1016/j.jqsrt.2011.01.031, 2011.

Zelenyuk, A., Cai, Y., and Imre, D.: From Agglomerates of Spheres to Irregularly Shaped Particles: Determination of Dynamic Shape Factors from Measurements of Mobility and Vacuum Aerodynamic Diameters, Aerosol Sci. Technol., 40, 197217, https://doi.org/10.1080/02786820500529406, 2006.

Zieger, P., Fierz-Schmidhauser, R., Gysel, M., Ström, J., Henne, S., Yttri, K. E., Baltensperger, U., and Weingartner, E.: Effects of relative humidity on aerosol light scattering in the Arctic, Atmos. Chem. Phys., 10, 3875-3890, https://doi.org/10.5194/acp10-3875-2010, 2010.

Zieger, P., Fierz-Schmidhauser, R., Weingartner, E., and Baltensperger, U.: Effects of relative humidity on aerosol light scattering: results from different European sites, Atmos. Chem. Phys., 13, 10609-10631, https://doi.org/10.5194/acp-13-106092013, 2013.

Zieger, P., Väisänen, O., Corbin, J. C., Partridge, D. G., Bastelberger, S., Mousavi-Fard, M., Rosati, B., Gysel, M., Krieger, U. K., Leck, C., Nenes, A., Riipinen, I., Virtanen, A., and Salter, M. E.: Revising the hygroscopicity of inorganic sea salt particles, Nat. Commun., 8, 15883, https://doi.org/10.1038/ncomms15883, 2017. 